\title{
Nominal Reference, Temporal Constitution and Quantification in Event Semantics*
}

Manfred Krifka

\section{INTRODUCTION}

It is by now a well-known topic in semantics that there are striking similarities between the meanings of nominal and verbal expressions, insofar as the mass:count distinction in the nominal domain is reflected in the atelic:telic distinction in the verbal domain (cf. Leisi 1953, Taylor 1977, Bach 1986, to cite just a few authors). However, these supposed similarities have not be made explicit in formal representations.

To do so, some terminological clarifications are in order. Most important is that it is not exactly the mass:count distinction, that is, the distinction between mass nouns like beer and count nouns like book, which is relevant for our discussion. One should compare instead expressions like beer and $a$ book, or books and five books, or beer and a glass of beer. The first element in each pair has the property of referring cumulatively (cf. Quine 1960); for instance, if there are two entities to which beer applies, this predicate applies to their collection as well. The second member of each pair does not have this property; for instance, if there are two (different) entities to which $a$ book applies, this predicate does not apply to their collection. I will call these predicates cumulative and quantized, respectively, and subsume this distinction under the heading of nominal reference.

The corresponding verbal distinction between atelic and telic predicates (or 'activities' and 'accomplishments' in the classification of Vendler 1957) will be subsumed under the heading of temporal constitution, following François (1985). To give a preliminary definition: A verbal expression is atelic if its denotation has no set terminal point (e.g. walk); it is telic if it includes a terminal point (e.g. solve the puzzle). This semantic distinction is parallelled by a battery of syntactic tests (cf. Dowty 1979). For example, in normal, that is, non-iterative interpretations, atelic expressions allow for durative adverbials (e.g. for ten minutes), but do not allow for timespan adverbials (e.g. in ten minutes), whereas with telic expressions the situation is reversed. 
(1) a. Mary walked (for ten minutes) $/(*$ in ten minutes).

b. Mary solved the puzzle (*for ten minutes)/(in ten minutes).

The relation between nominal reference and temporal constitution is apparent from two things. First, there is a semantic similarity between the two. For example, a quantized NP like a book denotes an object with precise limits, just as solve the puzzle denotes an event with precise limits. On the other hand, a cumulative NP like beer denotes something without clear limitation, just like what walk denotes also has no clear limitation. Second, it has been observed that the nominal reference type of verbal arguments often controls the temporal constitution of the complex verbal expression. Typically, a quantized argument yields a telic verbal predicate, and a cumulative argument yields an atelic verbal predicate:

(2) a. Mary drank beer (for ten minutes) $/\left({ }^{*}\right.$ in ten minutes).

b. Mary drank a glass of beer (*for ten minutes)/(in ten minutes).

The first to investigate the effect of the verbal arguments in detail was Verkuyl (1972). He tried to deal with it in the spirit of Generative Semantics with the help of features like [+SPECIFIED QUANTITY], which are projected from the argument to the verb. A similar theory was proposed by Platzack (1979). Dowty (1979) rightly criticized these feature-based approaches: They merely describe the facts, but do not really explain them, as one could choose any features and feature projection rules. Dowty himself, as well as Hoepelman (1976) and Hoepelman \& Rohrer (1980), developed theories in the paradigm of model-theoretic semantics to capture the facts in a more explanative way. I cannot go into these theories here in detail (see Krifka 1986). It seems to me that the general insight of the feature-based approach, namely that the nominal arguments and the complex verbal expression have something in common, is lost in them. The approach presented here is more in the spirit of ter Meulen (1984) and Bach (1986), who have tried to characterize the similarities of noun denotations and verb denotations in a model-theoretic semantics. Only they remain at a rather informal level, whereas I try to be more explicit. There is one explicit model-theoretic approach which looks similar to the one developed here, namely Hinrichs (1985). But Hinrichs' theory crucially depends on the notion of a stage of an individual, which complicates his formalizations and has some un-intuitive side effects. Other approaches, which were developed independently, are Verkuyl (1988), Dowty (1987b), and Link (1987).

\section{SOME THEORETICAL PREREQUISITES: LATTICES AND MEASURE FUNCTIONS}

In the following, the notions of structured individual domains and measure functions will play a central role. The basic structure, which was developed in Link (1983), is a certain type of lattice in which the distinction between cumulative and quantized reference can be captured in a formal way. I assume an extensional type-theoretic language with function symbols and identity as a representation language; the structures we need will be characterized with the means of this language itself, to keep things simple.

Assume that we have in our representation language a certain predicate $\mathbf{S}$ which characterizes individuals of a certain sort, for example objects in contrast to events. Then the extension of $\mathbf{S}$ should have the structure of a complete join semi-lattice without bottom element. This structure can be defined with the help of some additional symbols in the representation language, which are indexed by $\mathbf{S}$. Let $U_{S}$ be a two-place operation (the join), and $\subseteq_{S}, \subset_{S},{ }^{\circ}$ two-place relations (part, proper part, and overlap). Then the following definitions must hold as postulates for any admissible interpretation (with $\mathrm{x}, \mathrm{y}, \mathrm{z}, \mathrm{x}^{\prime}$ etc. as variables ranging over the extension of $\mathbf{S}$ :

(D 1) $\forall \mathrm{x} \forall \mathrm{y}\left[\mathrm{S}(\mathrm{x}) \wedge \mathrm{S}(\mathrm{y}) \rightarrow \exists \mathrm{z}\left[\mathrm{x} \cup_{\mathrm{s}} \mathrm{y}=\mathrm{z}\right]\right]$

(D 2) $\forall x \forall y\left[x \cup_{s} y=y \cup_{S} x\right]$

(D 3) $\forall x \forall y\left[x \cup_{S} x=x\right]$

(D 4) $\forall x \forall y \forall z\left[x \cup_{s}\left[y \cup_{s} z\right]=\left[x \cup_{s} y\right] \cup_{s} z\right]$

(D 5) $\forall \mathrm{x} \forall \mathrm{y}\left[\mathrm{x} \subseteq_{\mathrm{s}} \mathrm{y} \rightarrow \mathrm{x} \cup_{\mathrm{s}} \mathrm{y}=\mathrm{y}\right]$

(D 6) $\neg \exists x \forall y[x \subseteq s y]$

(D 7) $\forall \mathrm{x} \forall \mathrm{y}\left[\mathrm{x} \subset_{\mathrm{s}} \mathrm{y} \rightarrow \mathrm{x} \subseteq_{\mathrm{s}} \mathrm{y} \wedge \neg \mathrm{x}=\mathrm{y}\right]$

(D 8) $\forall x \forall y\left[x^{\circ}{ }_{s} y \rightarrow \exists z\left[z \subseteq_{S} x \wedge z \subseteq_{S} y\right]\right]$

(completeness)

(commutativity)

(idempotency)

(associativity)

(part)

(no bottom element)

(proper part)

(overlap)

(D 9) $\forall x \forall y\left[x \subset_{S} y \rightarrow \exists x^{\prime}\left[\neg x^{\circ}{ }_{S} x^{\prime} \wedge x \cup_{S} x^{\prime}=y\right]\right]$ (relative complementarity)

The join operation can be generalized to the fusion operation, which maps a set to its lowest upper bound. Here, $\mathrm{P}$ is a variable of the type of firstorder predicates which applies to entities of the sort $\mathbf{S}$.

(D 10) $\forall x \forall P\left[F U_{S}(P)=x \rightarrow \forall x^{\prime}\left[P\left(x^{\prime}\right) \rightarrow x^{\prime} \subseteq_{S} x\right] \wedge\right.$

$$
\left.\left.\forall \mathrm{x}^{\prime \prime}\left[\forall \mathrm{x}^{\prime}\left[\mathrm{P}\left(\mathrm{x}^{\prime}\right) \rightarrow \mathrm{x}^{\prime} \subseteq_{S} \mathrm{x}^{\prime \prime}\right] \rightarrow \mathrm{x} \subseteq_{S} \mathrm{x}^{\prime \prime}\right]\right]\right]
$$

We now define some higher-order predicates and relations to characterize different reference types. 
(D 11) $\forall \mathrm{P}[\mathrm{SNG}(\mathrm{P}) \leftrightarrow \exists \mathrm{x}[\mathrm{P}(\mathrm{x}) \wedge \forall \mathrm{y}[\mathrm{P}(\mathrm{y}) \rightarrow \mathrm{x}=\mathrm{y}]]]$

(P has singular reference)

$\left(D\right.$ 12) $\forall \mathrm{P}\left[\mathbf{C U M} \mathbf{M}_{\mathrm{S}}(\mathrm{P}) \rightarrow \forall \mathrm{x} \forall \mathrm{y}\left[\mathrm{P}(\mathrm{x}) \wedge \mathrm{P}(\mathrm{y}) \rightarrow \mathrm{P}\left(\mathrm{x} \cup_{\mathrm{s}} \mathrm{y}\right)\right]\right]$

( $P$ has cumulative reference)

(D 13) $\forall \mathrm{P}\left[\mathrm{SCUM}_{\mathrm{S}}(\mathrm{P}) \rightarrow \mathrm{CUM}_{\mathrm{S}}(\mathrm{P}) \wedge{ }_{\mathrm{SNNG}}(\mathrm{P})\right]$

(P has strictly cumulative reference)

(D 14) $\forall \mathrm{P}\left[\mathrm{QUA} \mathrm{A}_{\mathrm{S}}(\mathrm{P}) \rightarrow \forall \mathrm{x} \forall \mathrm{y}\left[\mathrm{P}(\mathrm{x}) \wedge \mathrm{P}(\mathrm{y}) \rightarrow \neg \mathrm{y} \subset_{\mathrm{S}} \mathrm{x}\right]\right]$

( $P$ has quantized reference)

$(\mathrm{D} 15) \forall \mathrm{P}\left[\mathrm{SQUA} \mathbf{A}_{\mathrm{S}}(\mathrm{P}) \rightarrow \mathrm{QUA}_{\mathrm{S}}(\mathrm{P}) \wedge \forall \mathrm{x}\left[\mathrm{P}(\mathrm{x}) \rightarrow \exists \mathrm{y}\left[\mathrm{y} \subset_{\mathrm{S}} \mathrm{x}\right]\right]\right]$

(P has strictly quantized reference)

(D 16) $\forall \mathrm{P}\left[\mathrm{DIV} \mathrm{V}_{\mathrm{S}}(\mathrm{P}) \leftrightarrow \forall \mathrm{x} \forall \mathrm{y}\left[\mathrm{P}(\mathrm{x}) \wedge \mathrm{y} \subseteq_{\mathrm{S}} \mathrm{x} \rightarrow \mathrm{P}(\mathrm{y})\right]\right]$

( $\mathrm{P}$ has divisive reference)

(D 17) $\forall \mathrm{x} \forall \mathrm{P}\left[\mathrm{ATOM} \mathrm{M}_{\mathrm{S}}(\mathrm{x}, \mathrm{P}) \rightarrow \mathrm{P}(\mathrm{x}) \wedge \neg \exists \mathrm{y}\left[\mathrm{y} \subset_{\mathrm{S}} \mathrm{x} \wedge \mathrm{P}(\mathrm{y})\right]\right]$

( $\mathrm{x}$ is a $\mathrm{P}$-atom)

$\left(D\right.$ 18) $\forall \mathrm{P}\left[\mathbf{A T M}_{\mathrm{S}}(\mathrm{P}) \rightarrow \forall \mathrm{x}\left[\mathrm{P}(\mathrm{x}) \rightarrow \exists \mathrm{y}\left[\mathrm{y} \subseteq_{\mathrm{S}} \mathrm{x} \wedge \operatorname{ATOM}_{\mathrm{S}}(\mathrm{y}, \mathrm{P})\right]\right]\right]$

(P has atomic reference)

(D 19) $\forall \mathrm{x} \forall \mathrm{y}\left[\mathbf{A T P}_{\mathrm{S}}(\mathrm{x}, \mathrm{y}) \leftrightarrow \mathrm{x} \subseteq_{\mathrm{s}} \mathrm{y} \wedge \operatorname{ATOM}_{\mathrm{S}}(\mathrm{x}, \mathbf{S})\right]$

( $\mathrm{x}$ is an atomic part of $\mathrm{y}$ in sort $\mathbf{S}$ ).

The following theorems hold, as can be easily checked ( $\mathrm{P}$ is assumed to be restricted to $\mathbf{S}$ ):

(T 1) $\quad \forall \mathrm{P}\left[\mathrm{SNG}(\mathrm{P}) \rightarrow \mathrm{QUA}_{\mathrm{S}}(\mathrm{P})\right]$

(T 2) $\quad \forall \mathrm{P}\left[\mathrm{SNG}(\mathrm{P}) \rightarrow \mathrm{CUM}_{\mathrm{S}}(\mathrm{P})\right]$

(T 3) $\forall \mathrm{P}\left[\mathrm{QUA} \mathbf{A}_{\mathrm{S}}(\mathrm{P}) \rightarrow \neg_{\mathrm{SCUM}}(\mathrm{P})\right]$

(T 4) $\forall \mathrm{P}\left[\mathrm{QUA} \mathbf{A}_{\mathrm{S}}(\mathrm{P}) \rightarrow \operatorname{ATM}_{\mathrm{S}}(\mathrm{P})\right]$

To handle expressions like five ounces of gold, we will need measure functions (cf. Cartwright 1975). Therefore the representation language must contain names for the real numbers and for the standard arithmetical operations and relations. Measure functions are functions (possibly partial) from individuals to numbers which preserve certain structures in the object domain (cf. e.g. Suppes \& Zinnes 1963). For any measure function $\mu$ (e.g., degrees Celsius), there is a preorder $\precsim \mu$ (e.g. 'equal or less warm than') such that this order is reflected in the $\leq$-order of the reals.

(D 20) $\forall \mathrm{R}\left[\mathrm{PREO}_{\mathrm{S}}(\mathrm{R}) \leftrightarrow \forall \mathrm{x} \forall \mathrm{y} \forall \mathrm{z}[\mathrm{R}(\mathrm{x}, \mathrm{x}) \wedge[\mathrm{R}(\mathrm{x}, \mathrm{y}) \wedge \mathrm{R}(\mathrm{y}, \mathrm{z}) \rightarrow \mathrm{R}(\mathrm{x}, \mathrm{z})]]\right]$ ( $R$ is a preorder in $S$ )

(D 21) $\forall \mathrm{m} \forall \mathrm{R}\left[\mathrm{MF}_{\mathrm{S}}(\mathrm{R}, \mathrm{m}) \rightarrow \mathrm{PREO}_{\mathrm{S}}(\mathrm{R}) \wedge \forall \mathrm{x} \forall \mathrm{n}[\mathrm{m}(\mathrm{x})=\mathrm{n} \rightarrow \mathrm{S}(\mathrm{x}) \wedge \mathbb{R}(\mathrm{n})]\right.$ $\wedge \forall \mathrm{x} \forall \mathrm{y}[\mathrm{R}(\mathrm{x}, \mathrm{y}) \leftrightarrow \mathrm{m}(\mathrm{x}) \leq \mathrm{m}(\mathrm{y})]]$

( $\mathrm{m}$ is a(n ordinal) measure function on $\mathbf{S}$ with respect to $\mathrm{R}$ )
There is a certain class of measure functions of special interest, namely measure functions which are extensive relative to a concatenation operation and a preorder relation. The concatenation $+_{\mu}$ of a measure function $\mu$ is correlated with arithmetical addition.

$\left(\mathrm{D}\right.$ 22) $\forall \mathrm{C}\left[\mathrm{CONC}_{\mathrm{S}}(\mathrm{C}) \rightarrow \forall \mathrm{x} \forall \mathrm{y}[\mathrm{C}(\mathrm{x}, \mathrm{y})=\mathrm{C}(\mathrm{y}, \mathrm{x}) \wedge \mathrm{S}(\mathrm{C}(\mathrm{x}, \mathrm{y}))]\right]$ ( $C$ is a concatenation in $S$ )

(D 23) $\forall \mathrm{m} \forall \mathrm{R} \forall \mathrm{C}\left[\mathrm{EMF}_{\mathrm{S}}(\mathrm{R}, \mathrm{C}, \mathrm{m}) \rightarrow \mathrm{MF}_{\mathrm{S}}(\mathrm{R}, \mathrm{m}) \wedge \operatorname{CONC}_{\mathrm{S}}(\mathrm{C}) \wedge\right.$ $\forall \mathrm{x} \forall \mathrm{y} \forall \mathrm{z}[\mathrm{C}(\mathrm{x}, \mathrm{y})=\mathrm{z} \rightarrow \mathrm{R}(\mathrm{x}, \mathrm{z})]]$

(extensive measure function)

(D 24) $\forall \mathrm{m} \forall \mathrm{R} \forall \mathrm{C}\left[\mathrm{EMF}_{\mathrm{S}}(\mathrm{R}, \mathrm{C}, \mathrm{m}) \rightarrow \forall \mathrm{x} \forall \mathrm{y} \forall \mathrm{z}[\mathrm{C}(\mathrm{x}, \mathrm{y})=\mathrm{z} \leftrightarrow\right.$ $\mathrm{m}(\mathrm{x})+\mathrm{m}(\mathrm{y}) \doteq \mathrm{m}(\mathrm{z})]]$

(additivity)

(D 25) $\forall \mathrm{m} \forall \mathrm{R} \forall \mathrm{C}\left[\mathrm{EMF}_{\mathrm{S}}(\mathrm{R}, \mathrm{C}, \mathrm{m}) \rightarrow \forall \mathrm{x} \forall \mathrm{y}[\mathrm{R}(\mathrm{x}, \mathrm{y}) \rightarrow \mathrm{n}[\mathrm{n}>0 \wedge \mathrm{n} \bullet \mathrm{m}(\mathrm{x})>\right.$ $\mathrm{m}(\mathrm{y})]]]$

(Archimedian property)

(D 24) says that $m$ denotes an additive measure function with respect to C. For example, if two objects have a weight of 2 and $3 \mathrm{~kg}$ respectively, then their concatenation has the weight of $5 \mathrm{~kg}$. (D 25) says that entitities in R-relation have to be commensurable with each other. One obvious consequence of this is that any extensive measure function has values greater 0 for entities which stand in its preorder relation, that is, for entities to which it can be reasonably applied.

\section{(T 5) $\forall \mathrm{m} \forall \mathrm{R} \forall C \forall \mathrm{x} \forall \mathrm{y}\left[\mathrm{EMF}_{\mathrm{s}}(\mathrm{R}, \mathrm{C}, \mathrm{m}) \wedge \mathrm{R}(\mathrm{x}, \mathrm{y}) \rightarrow \mathrm{m}(\mathrm{x})>0 \wedge \mathrm{m}(\mathrm{y})>0\right]$}

How can we combine extensive measure functions with the lattice structure developed above? First, the preorder $\precsim_{\mu}$ should be a continuation of the part relation $\varsigma_{S}$. Second, the concatenation $+_{\mu}$ can be defined as join $\cup_{S}$ restricted to non-overlapping individuals. This restriction is necessary, because otherwise $\mu$ would measure the overlap individual twice. Note that this is not a real restriction in complementary lattices, as we can find for any two overlapping individuals $x, y$ two non-overlapping individuals $x, y^{\prime}$ (with $y^{\prime}$ the remainder of $y$ if $x$ is subtracted) such that $x \cup_{s} y$ $=\mathrm{x} \cup \mathrm{s} \mathrm{y}^{\prime}$.

(D 26) $\forall \mathrm{m} \forall \mathrm{R} \forall \mathrm{C}\left[\mathrm{EMF}_{\mathrm{S}}(\mathrm{R}, \mathrm{C}, \mathrm{m}) \rightarrow \forall \mathrm{x} \forall \mathrm{y}\left[\mathrm{x} \subseteq_{\mathrm{S}} \mathrm{y} \rightarrow \mathrm{R}(\mathrm{x}, \mathrm{y})\right]\right]$

(D 27) $\forall \mathrm{m} \forall \mathrm{R} \forall \mathrm{C}\left[\mathrm{EMF}_{\mathrm{S}}(\mathrm{R}, \mathrm{C}, \mathrm{m}) \rightarrow \forall \mathrm{x} \forall \mathrm{y}\left[\neg \mathrm{x}^{\circ}{ }_{\mathrm{s}} \mathrm{y} \rightarrow \mathrm{C}(\mathrm{x}, \mathrm{y})=\mathrm{x} \cup_{\mathrm{s}} \mathrm{y}\right]\right]$ 
Extensive measure functions which satisfy these conditions will be called compatible with the respective lattice. ${ }^{1}$

As a basic result, it can be shown that predicates which are restricted by a measure function compatible with the relevant lattice are quantized:

\section{(T 6) $\left.\forall \mathrm{m} \forall \mathrm{n} \forall \mathrm{R} \forall \mathrm{C}\left[\mathrm{EMF}_{\mathrm{S}}(\mathrm{R}, \mathrm{C}, \mathrm{m})\right] \rightarrow \mathrm{QUA}_{\mathrm{S}}(\lambda \mathrm{x}[\mathrm{m}(\mathrm{x})=\mathrm{n}])\right]$}

Proof: Take a measure function $\mu$ and a positive number such that $\mathbf{E M F}_{\mathrm{s}}\left(\leq_{\mu},+_{\mu}, \mu\right)$ and assume to the contrary that $\lambda \mathrm{x}[\mu(\mathrm{x})=v]$ is not quantized, that is, there are two individuals $\mathrm{x}_{1}, \mathrm{x}_{2}$ with $\mathrm{x}_{2} \subset_{\mathrm{S}} \mathrm{x}_{1}, \mu\left(\mathrm{x}_{1}\right)=v$, $\mu\left(\mathrm{x}_{2}\right)=v$. Because of relative complementarity (D.9), there is an $\mathrm{x}_{3}$ with $\neg \mathrm{x}_{2}{ }_{\mathrm{S}}^{\circ} \mathrm{x}_{3}$ and $\mathrm{x}_{2} \cup_{\mathrm{S}} \mathrm{x}_{3}=\mathrm{x}_{1}$, that is, according to the definition of $+_{\mu}$ (D 27), $\mathrm{x}_{1}=\mathrm{x}_{2}+{ }_{\mu} \mathrm{x}_{3}$. Because of additivity (D 24) it holds that $\mu\left(\mathrm{x}_{1}\right)=$ $\mu\left(\mathrm{x}_{2}\right)+\mu\left(\mathrm{x}_{3}\right)=v$. On the other hand, according to our assumption it holds that $\mu\left(\mathrm{x}_{2}\right)=v$; from $\mathrm{x}_{3} \subset_{S} \mathrm{x}_{1}$ it follows that $\mathrm{x}_{3} \leq_{\mu} \mathrm{x}_{1}$ by (D 26), hence by Archimedian property (D 25), $\mu\left(\mathrm{x}_{3}\right)>0$; and therefore $\mu\left(\mathrm{x}_{2}\right)+\mu\left(\mathrm{x}_{3}\right)=$ $\mu\left(\mathrm{x}_{1}\right)>v$. Thus, we arrive at the contradiction $\mu\left(\mathrm{x}_{1}\right)=v$ and $\mu\left(\mathrm{x}_{1}\right)>v$.

Lattice structures as developed above can be related in various ways to each other. One particular relation is especially important, as it captures the notion of granularity as sketched in Link (1987). The idea is that a sort $\mathbf{S}$ is more fine-grained than a sort $\mathbf{P}$ if $\mathbf{P}$ is a subsort of of $\mathbf{S}$ (that is, $\mathbf{P}(\mathrm{x}) \rightarrow \mathbf{S}(\mathrm{x})$ ), and $\subseteq_{\mathrm{P}}$ is a subrelation of $\subseteq_{\mathrm{S}}$ (that is, $\mathrm{x} \subseteq_{\mathrm{P}} \mathrm{y} \rightarrow \mathrm{x} \subseteq_{\mathrm{S}} \mathrm{y}$ ). Especially, there can be entities in $\mathbf{S}$ which are $\subset_{\mathbf{S}}$-parts of $\mathbf{P}$-atoms. The notion of different granularities can be applied in cases where an entity appears as atomic under one description and as composed of different entities under another description. For example, an arrival of a train at a station may be considered as atomic event or as an event which is composed of subevents.

A final basic concept, which will be only sketched here, are derived measure functions. Basically, they describe the transfer of a measure function from one sort to another (an example will be measure functions for times used as measure functions for events, see section 5). Assume that we have two sorts, $\mathbf{S}, \mathbf{P}$, and an extensive measure function $\sigma$ compatible with $\mathbf{S}$, that is, there is a preorder $\precsim_{\sigma}$ and a concatenation $+_{\sigma}$ with $\operatorname{EMF}_{\mathrm{S}}\left(\precsim_{\sigma},+_{\sigma}, \sigma\right)$. Assume furthermore that there is a homomorphism $\mathrm{h}$ from $\mathbf{S}$ to $\mathbf{P}$, with $\mathrm{h}\left(\mathrm{x} \cup_{\mathrm{S}} \mathrm{y}\right)=\mathrm{h}(\mathrm{x}) \cup_{\mathrm{P}} \mathrm{h}(\mathrm{y})$. Then we can derive from $\sigma$ an extensive measure function $\pi$ compatible with $\mathbf{P}$ in two steps. First, $\pi$ is standardized by claiming $\forall \mathrm{x}[\pi(\mathrm{h}(\mathrm{x}))=\sigma(\mathrm{x})]$. This fixes the values of $\pi$ for the image of $h$. As the image of $h$ is not necessarily the whole sort $P$, we must in a second step generalize the measure function by specifying a preorder $\precsim_{\pi}$ and a concatenation $+_{\pi}$ for $\pi$ which are compatible with the standardization and which fix the values of $\pi$ for every element in $\mathbf{P}$ such that $\operatorname{EMF}_{\mathbf{P}}\left(\precsim_{\pi},+_{\pi}, \pi\right)$. The existence of such a derived measure function depends on the standard ing homomorphism $h$, and there is possibly more than one derived measure function which meets the requirements.

\section{THE SEMANTICS OF NOMINAL PREDICATES}

We will now apply the system of relations and operations developed above to the semantics of nominal predicates. Assume that we have a latticestructured sort characterized by $\mathbf{O}$, the sort of objects. I will not develop a full-fledged syntactic apparatus, but presuppose some standard categorial grammar notation and only hint at some conditions the syntax has to meet.

Mass nouns like gold are assigned to the basic syntactic category $\mathrm{N}$. They clearly should be translated as cumulative predicates, e.g. gold', with $\mathbf{C U M}_{\mathrm{O}}$ (gold'). It is unclear whether more restrictive translations can be assumed. Sometimes it has been claimed that at least some mass nouns hold divisively as well, that is in the example at hand, that all parts of gold are gold. On the other hand, it has been claimed that mass terms are atomic. I will not tackle the so-called minimal part problem here, but I think that a solution can be found following Link (1987), who took into account the granularity level. Then we can assume that mass nouns refer divisively relative to the current granularity level, but we do not have to commit ourselves to an atomic or a non-atomic conception of the world.

There is a construction which derives quantized predicates from mass nouns, the so-called measure construction, exemplified by five ounces of gold. The most plausible semantic analysis is that the phrase five ounces, call it the measure phrase, is an operator on the mass noun. Measure phrases, in turn, can be translated on the basis of a number, represented by the numeral (e.g. five) and a measure function, represented by the measure word (e.g. ounces). As for the syntax, I assume that numerals belong to a basic category NM, so that measure words have the category N/N,NM. Before I give a detailed semantics, one should note the following examples: 
(3) a. five ounces of gold

b. *twenty carats of gold

c. *five ounces of seven cube centimeters of gold

(3.b) shows that the measure function must be extensive. This can be captured in the formal representation if we assume that the measure noun is represented by an extensive measure function compatible with the object lattice. This is, of course, not the only restriction; sometimes a measure function is simply inadequate for stylistic reasons, e.g. *thousand liters of mortar, or *five hundred becquerel of milk. The point is that all acceptable measure functions seem to be necessarily extensive.

(3.c) shows that the head noun must meet certain conditions, too. One could, of course, exclude (3.c) syntactically by not allowing two measure phrases within the same level of a noun phrase, but we will see that an exclusion on semantic principles is more general, insofar as it will carry over to adverbial modification (cf. section 5). The reason why (3.c) is bad can be intuitively characterized as follows: The measure phrase serves to 'cut out' entities of a certain size from a continuum of entities which fall under the head noun. If the head noun is quantized, then there is no such continuum, and the application of the measure phrase therefore should be infelicitous.

This can be formalized (for an arbitrary sort $\mathbf{S}$ ) by using a special relation of 'quantizing modification' between a predicate and a predicate modifier, QMOD $_{\mathrm{s}}$, which is defined as in (D 28). It says that the modfier $P$ changes the nonquantized predicate $\mathrm{P}$ into the quantized predicate $P(\mathrm{P})$.

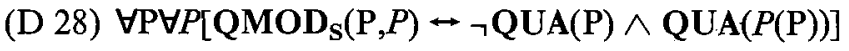

(quantizing modification)

A measure construction like five ounces (of) gold can be analyzed as in (4). Actually, the QMOD part establishes a well-formedness condition; for reason of simplicity, it is taken as a part of the assertion. For the same reason, I introduce of syncategorematically.

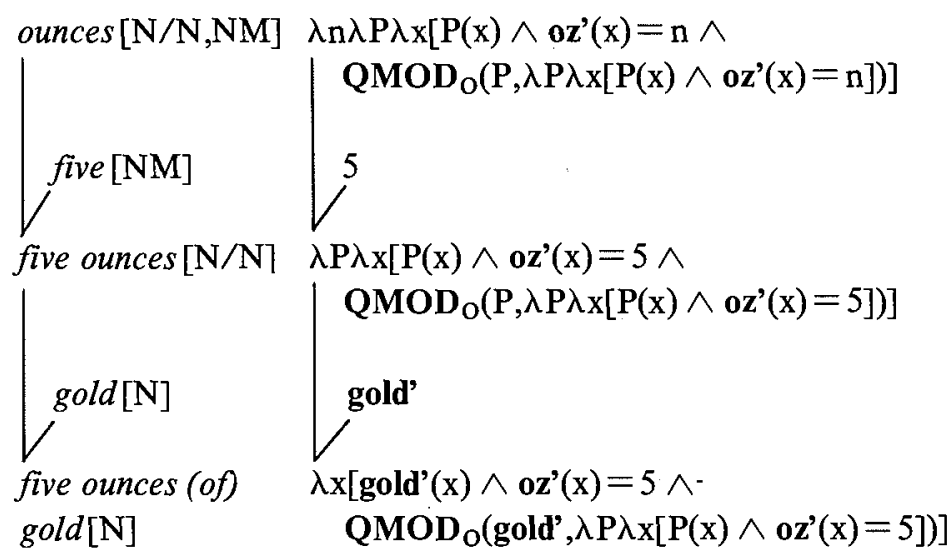

The well-formedness condition is satisfied because gold' is, as a representation of a mass noun, cumulative, and ounce should be translated by an extensive measure function, thus making the modifier $\lambda \mathrm{P} \lambda \mathrm{x}[\mathrm{P}(\mathrm{x})$ $\wedge \mathbf{o z}(\mathrm{x})=5$ ] a quantizing one (cf. $\mathrm{T}$ 6). It follows that predicates like (4) are quantized themselves. From this fact we can derive that measure phrases cannot be iterated as in (3.c), as the nominal predicate to which they apply must not be quantized.

There are more types of nominal constructions which can be analyzed similar to five ounces of gold, e.g. five glasses of wine or five spoonfuls of flour. Here, the measure function is perhaps not as standardized as ounce, but it nevertheless satisfies additivity and the Archimedian property, at least in principle. ${ }^{2}$ But then there are so-called classifier constructions like five head of cattle, which are rare in European languages but abound in languages like Chinese (an exam ple is sān zhāng zhuōzi 'three CLASS table", "three tables"). The main difference from ordinary measure constructions is that in classifier constructions, the measure function depends on the head noun. I assume that the representation language has a function symbol NU, for 'Natural Unit', which yields extensive measure functions compatible with the object lattice when applied to nominal predicates. To give an example (without the well-formedness conditions):

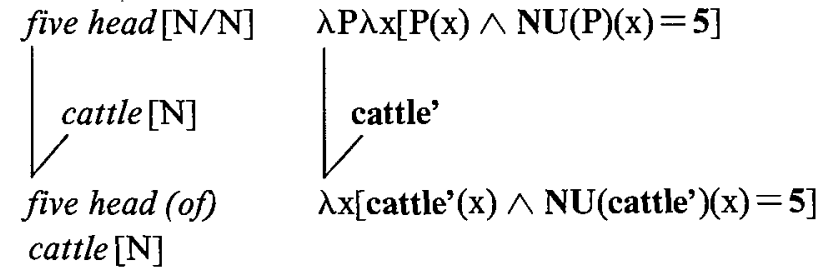

(with $\exists R \exists C\left[\mathbf{E M F}_{\mathbf{o}}(\mathrm{R}, \mathrm{C}, \mathrm{NU}(\text { cattle') })]^{\prime}\right.$ 
The semantic representation of (5) consists of two 'criteria of applicability', a qualitative criterion, which is represented by the head noun, cattle, and semantically by the cattle'(x), and a quantitative criterion, which is introduced by the classifier phrase, five head (of), and represented semantically by $\mathbf{N U}\left(\right.$ cattle'$\left.^{\prime}\right)(\mathrm{x})=\mathbf{5}$.

(5) is a preliminary representation in several respects. An important point is that NU cannot reasonably be applied to any predicate whatsoever, but only to those predicates which correspond to some kind; for example, NU should not have a value for the predicate $\lambda x\left[\right.$ cattle' $^{\prime}(x) \vee$ lettuce' $\left.(x)\right]$, because the natural units of cattle and lettuce are rather different. In classifier languages, this may be reflected by the fact that most classifiers can be applied only to nouns which denote entities of a certain type, e.g. big animals or flat objects (cf. e.g. Allan 1977, Kölver 1982).

It seems to be redundant to demand both cattle' $(x)$ and $N U\left(\right.$ cattle' $\left.^{\prime}\right)(x)=5$, as one could argue that only cattle can be measured by the measure function NU(cattle') in the first place. This would mean that we could replace the qualitative criterion by a sufficiently constrained quantitative criterion. But I think it is reasonable to keep to these two distinct criteria, as we can assume that NU yields the same measure function for entities of a similar kind. For example, the unit for all living beings is constituted by the organism. Then, NU(cattle') and NU(game') should denote the same measure function, whereas the qualitative criterion represented by the nominal predicate distinguishes between five head of cattle and five head of game.

A final point is that NU cannot reasonably be applied to the extension of mass nouns, as intensionally different mass nouns may have the same extension. In a more adequate representation, NU should therefore be applied to the intension of the mass noun.

Let us now consider count noun constructions, like five cows. As languages like Chinese use classifier constructions to express these predicates, count noun constructions should be represented similar to classifier constructions. They both are, so to speak, different syntactic means of arriving at the same semantic end. The main difference to classifier constructions is that the reference to a natural unit (that is, the quantitative criterion of application) is built into the head noun, making it a count noun. Compare (6) with (5):
(6)

$$
\int_{f i v e[\mathrm{NM}]}^{\operatorname{cow}[\mathrm{N} / \mathrm{NM}]}
$$

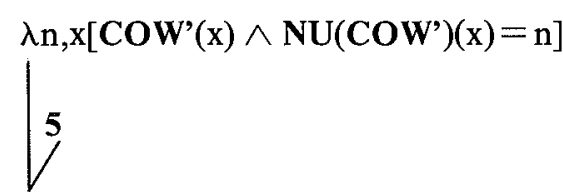

Here, COW' is a nominal predicate similar to cattle', which underlies the English count noun cow, but which has no surface representation in the English lexicon. ${ }^{3}$

The analysis of count nouns presented in (6) basically says that count nouns are two-place relations between numbers and entities, whereas mass nouns are one-place predicates. In the following, I will neglect the internal constituency of count nouns and simply present them as relations, e.g. the count noun cow as $\lambda \mathrm{n} \lambda \mathrm{xcow}^{\prime}(\mathrm{x}, \mathrm{n})$, with $\operatorname{cow}^{\prime}(\mathrm{x}, \mathrm{n}) \leftrightarrow \mathrm{COW}^{\prime}(\mathrm{x}) \wedge$ $\mathrm{NU}\left(\mathrm{COW}^{\prime}\right)(\mathrm{x})=\mathrm{n}$.

Count nouns usually come in two morphological forms, singular and plural. But in examples like (6), the plural is triggered syntactically and has no semantic effect at all. This can be seen in plural count noun constructions like $0 \mathrm{cows} /{ }^{*} \operatorname{cow}$ and $1.0 \operatorname{cows} /{ }^{*} \operatorname{cow}$, which have nothing to do with the semantic concept of plurality, but are easily explained if one assumes that the numerals 0 and 1.0 trigger syntactic plurality.

But there are bare plurals like cows, as in Mary saw cows. Here, the plural has at least the effect of binding the number argument of count nouns, making them one-place predicates. It is clear that the number variable $\mathrm{n}$ should be existentially quantified. It can be argued that it should furthermore be specified as greater than 1. But there are examples which show that bare plurals can also be used in case the number of objects is one, and even less then one:

a. Do you have children?

Yes, I have one child. /*No, I have (only) one child.

b. Did you eat apples today?

Yes, I ate half an apple. $/ *$ No, I ate (only) half an apple.

The only restriction, it appears, is that the entity to which a bare plural can apply must be 'more than $0^{\prime}$ '. But this we have claimed for extensive measure functions if they apply at all (cf. T 6). We therefore get the following representation:

(8) $\quad \operatorname{cows}[\mathrm{N}] \quad \lambda \mathrm{x} \exists \mathrm{n}\left[\operatorname{cow}^{\prime}(\mathrm{x}, \mathrm{n})\right](=$ cows', for short $)$ 
But why, then, does a speaker of English use the singular form $a$ cow if he has enough evidence that the number of entities he has in mind is one? The reason is, I think, a pragmatic one. Under the reconstruction developed here, a cow is more informative than cows, and it is reasonable to assume that a speaker chooses the more informative expression if it is truthfully applicable and if it is not more complex than the less informative expression. The essence of this pragmatic rule was formulated in Horn (1972) and Atlas \& Levinson (1981); it can be derived from the first part of the maxim of Quantity (Grice 1967, 'make your contribution as informative as is required'), with the maxims of Quality ('do not say that for which you lack adequate evidence') and Relevance ('be brief') as interacting principles. In short, this pragmatic rule can be stated as follows:

\section{Pragmatic Rule I:}

If two expressions $\alpha, \beta$ are (i) both applicable, (ii) $\alpha$ is more specific than $\beta$, (iii) $\alpha$ is not more complex than $\beta$, then choose $\alpha$.

With our analysis, a cow is semantically clearly more specific than cows. And one can argue that $a$ cow is not more complex than cows: although a cow consists of two words, cows is morphologically marked. Therefore the hearer can implicate that the speaker does not have a single cow in mind when he uses cows and can be supposed to have enough evidence for the number of the entities he refers to. ${ }^{4}$

One can show that bare plurals come out as cumulative predicates in this approach. Sketch of the proof: Assume the bare plural representation $\phi=\lambda \mathrm{x} \exists \mathrm{n}[\mu(\mathrm{x})=\mathrm{n}]$, where $\mu$ is an extensive measure function, and $\mathrm{x}_{1}$, $\mathrm{x}_{2}$ with $\phi\left(\mathrm{x}_{\mathrm{I}}\right), \phi\left(\mathrm{x}_{2}\right)$. That is, there are numbers $\mathrm{n}_{1}, \mathrm{n}_{2}$ with $\mu\left(\mathrm{x}_{\mathrm{I}}\right)=\mathrm{n}_{1}$ and $\mu\left(\mathrm{x}_{2}\right)=\mathrm{n}_{2}$. If $\mathrm{x}_{1}$ and $\mathrm{x}_{2}$ do not overlap, $\neg \mathrm{x}_{\mathrm{I}}{ }^{\circ}{ }_{\mathrm{O}} \mathrm{x}_{2}$, then according to (D 27), (D 24) $\mu\left(\mathrm{x}_{1} \cup_{\mathrm{O}} \mathrm{x}_{2}\right)=\mathrm{n}_{1}+\mathrm{n}_{2}$, hence $\phi\left(\mathrm{x}_{1} \cup_{\mathrm{O}} \mathrm{x}_{2}\right)$. If they do overlap but are not identical, then one can find equivalent non-overlapping entities (because of relative complementarity D 9), e.g. $x_{1}, x_{3}$ with $\neg x_{1}{ }^{\circ}{ }_{0} x_{3}$ and $\mathrm{x}_{1} \cup_{\mathrm{O}} \mathrm{x}_{3}=\mathrm{x}_{1} \cup_{\mathrm{O}} \mathrm{x}_{2}$, and thus reduce this case to the first one. If $\mathrm{x}_{1}=\mathrm{x}_{2}$, then $x_{1}=x_{1} \cup \cup_{0} x_{2}$ because of idempotency (D 3), and therefore $\phi\left(x_{1} \cup \cup_{0} x_{2}\right)$. As these are all possibilities, we deduce $\operatorname{CUM}_{\mathbf{O}}(\phi)$.

This result explains the well-known fact that mass nouns and bare plurals behave semantically alike. For example, bare plurals meet the wellformedness conditions for measure phrases; and indeed, measure phrases are allowed, e.g. five herds of cows.

Finally, I will show how a problem with the representation of nominal expressions as developed above can be solved. Count noun expressions are, in general, represented by quantized predicates. But there are examples like $a$ twig or $a$ sequence ${ }^{5}$ which do not seem to be quantized, as e.g. a twig can have a proper part which is a twig as well. It appears that twig and, say, ounce behave differently, as a proper part of something which is one twig might be one twig as well, whereas a proper part of something which weighs five ounces cannot weigh five ounces.

This problem can be handled if we have different part relations, following Link (1983). Assume that we have two sorts, I for individual objects and $\mathrm{Q}$ for quantities of matter. Assume further that there is a function $\mathrm{h}$ which maps objects to the quantities of matter they consist of; $h$ denotes a function from the union of the extension of $\mathbf{I}$ and $\mathbf{Q}$ to the extension of $\mathbf{Q}$, with $\mathrm{Q}(\mathrm{x}) \rightarrow \mathrm{h}(\mathrm{x})=\mathrm{x}$ and $\mathrm{h}\left(\mathrm{x} \cup_{\mathrm{I}} \mathrm{y}\right)=\mathrm{h}(\mathrm{x}) \cup_{\mathrm{Q}} \mathrm{h}(\mathrm{y})$. In addition to the individual part $\subseteq_{I}$ and overlap ${ }_{I}{ }_{I}$ we can define a material part $\subseteq_{M}$ as $x \subseteq_{M} y \rightarrow h(x) \subseteq_{Q} h(y)$ and a corresponding material overlap ${ }^{\circ}$ as $x^{\circ}{ }_{M} y \rightarrow \exists z\left[z \subseteq_{M} \mathrm{X} \wedge \mathrm{z} \subseteq_{M} \mathrm{y}\right]$. Note that the material part and overlap are coarser than the individual part and overlap, as it might be the case that two objects overlap materially, but not individually.

Now, consider two extensive measure functions. oz' and tw' (which is short for $\lambda \mathrm{x} \iota n\left[\right.$ twig' $\left.^{\prime}(\mathrm{x}) \wedge \mathrm{NU}\left(\mathrm{twig}^{\prime}\right)(\mathrm{x})=\mathrm{n}\right]$, the inherent measure function of the count noun $t w i g)$. I assume that tw' is originally a measure function for $\mathrm{I}$, with the concatenation $+_{t}$ defined as $\neg \mathrm{X}^{\circ} \mathrm{I} \leftrightarrow\left[\mathrm{x}+{ }_{t} \mathrm{y}=\mathrm{x} \cup_{\mathrm{t}} \mathrm{y}\right]$. On the other hand, $I$ assume that $\mathbf{o z}$ ' is originally a measure function for $Q$ with concatenation ${ }_{\circ}$ defined as $\neg x^{\circ}{ }_{Q} \mathrm{y} \leftrightarrow\left[x+o y=x \cup_{Q} y\right]$, which can be extended to $I$ on virtue of $h$, that is, by the standardization formula $\mathbf{o z}^{\prime}(\mathrm{x})=\mathbf{o} \mathbf{z}^{\prime}(\mathrm{h}(\mathrm{x}))$ (cf. the discussion of derived measure functions in section 2). As concatenation operation ${ }_{0}$ for $I$ we have to assume a more restricted one, namely $\neg \mathrm{X}^{\circ} \mathrm{M} \leftrightarrow\left[\mathrm{x}+{ }_{\mathrm{o}} \mathrm{y}=\mathrm{x} \cup_{\mathrm{Q}} \mathrm{y}\right]$. This restriction to individuals which do not overlap materially is necessary to avoid conflicts with the standardization. Otherwise, if we have two individuals $x, y$ with $x^{o} \mathrm{y}$, then $\mathbf{o z}^{\prime}\left(\mathrm{x}_{\mathrm{I}} \mathrm{y}\right)$ would be $\mathbf{o z}^{\prime}(\mathrm{x})+\mathbf{o z ^ { \prime }}(\mathrm{y})$ by generalization, but $\mathbf{o z ^ { \prime }}\left(\mathrm{h}\left(\mathrm{x} \mathrm{x}_{\mathrm{I}} \mathrm{y}\right)\right)=$ $o z^{\prime}\left(h(x) \cup_{Q} h(y)\right) \neq o z^{\prime}(h(x))+o z^{\prime}(h(y))=o z^{\prime}(x)+o z^{\prime}(y)$ by standardization. Now consider a twig $x_{1}$, which contains another twig $x_{2}$ as a part. This relation can be captured by claiming $x_{2} \subseteq_{M} x_{1}$ and $\neg x_{2} \subseteq_{I} x_{1}$. Then it holds that $t^{\prime}\left(x_{1}\right)=1, t^{\prime}\left(x_{2}\right)=1$ and, as $x_{1}, x_{2}$ do not overlap individually, also $\mathbf{t w}^{\prime}\left(\mathrm{x}_{1} \cup_{0} \mathrm{x}_{2}\right)=2$, that is, $\mathbf{t w}^{\prime}\left(\mathrm{x}_{1} \cup_{\mathrm{o}} \mathrm{x}_{2}\right) \neq \mathbf{t} \mathbf{w}^{\prime}\left(\mathrm{x}_{1}\right)$. However, if $\mathbf{o z}$ ' is a measure function derived from a measure function for quantities of matter, it holds that $\mathbf{o z}\left(\mathrm{x}_{1} \cup_{\mathrm{I}} \mathrm{x}_{2}\right)=\mathbf{o z ^ { \prime }}\left(\mathrm{h}\left(\mathrm{x}_{1} \cup_{\mathrm{I}} \mathrm{x}_{2}\right)\right)=\mathbf{o z ^ { \prime }}\left(\mathrm{h}\left(\mathrm{x}_{1}\right) \cup_{\mathrm{Q}} \mathrm{h}\left(\mathrm{x}_{2}\right)\right)=\mathbf{o z ^ { \prime }}\left(\mathrm{h}\left(\mathrm{x}_{1}\right)\right)$, as $\mathrm{h}\left(\mathrm{x}_{2}\right)$ $\subseteq_{Q} h\left(x_{1}\right)$. This is consistent with the first result, as tw' and $\mathbf{o z}$ ' rely on different concatenation operations. They are measure functions of different dimensions, so to speak. Therefore, the claim that count nouns are based 
on extensive measure functions can be maintained even for problematic cases like twig.

\section{THE SEMANTICS OF TEMPORAL CONSTITUTION}

We now turn to the semantics of verbal predicates. In order to capture the well-known parallelism between nominal reference and temporal constitution, it is necessary to provide a denotation structure for verbal predicates which is similar to the denotation structure of nominal predicates. This can be done in a semantic framework in the tradition of Davidson (1967), who took events as basic entities. On these events, a lattice structure similar to the lattice structure for objects can be defined.

Unlike Davidson, but similar to Castañeda (1967) and many later works, e.g. Parsons (1980), Carlson (1984) and Dowty (1987a), I will represent (syntactic) verb arguments and adverbial attributes in the same manner, namely by means of primitive thematic relations. They are reconstructed as two-place relations between events and objects and capture thematic roles such as agent and patient. The following example shows some fundamentals of the semantic representation I have in mind 6

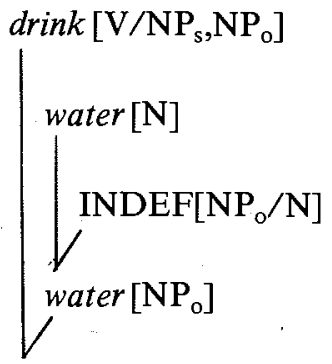

drink water $\left[\mathrm{V} / \mathrm{NP}_{\mathrm{s}}\right]$

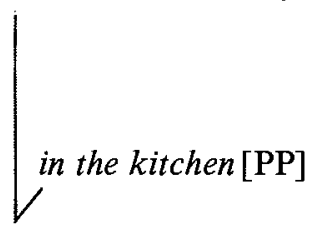

drink water in the kitchen $\left[\mathrm{V} / \mathrm{NP}_{\mathrm{s}}\right]$

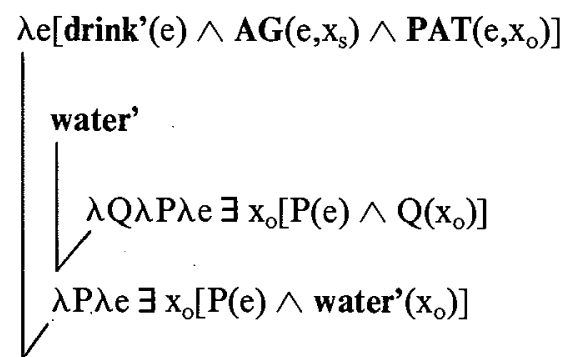

$\lambda \mathrm{e} \exists \mathrm{x}_{\mathrm{o}}\left[\right.$ drink' $^{\prime}(\mathrm{e}) \wedge \mathrm{AG}\left(\mathrm{e}, \mathrm{x}_{\mathrm{s}}\right) \wedge \mathbf{P A T}\left(\mathrm{e}, \mathrm{x}_{\mathrm{o}}\right)$

$\wedge$ water' $\left.\left(\mathrm{x}_{0}\right)\right]$

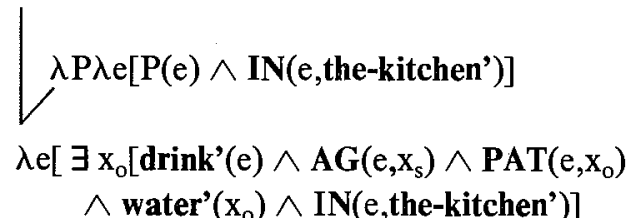

First, look at the syntactic tree at the left (which does not necessarily represent surface structure). I assume that verbal predicates have a specified

set of arguments which are related to specific syntactic functions like subject and object. The arguments are specified as to their syntactic function, which appear as suffixes of category names, here $s$ and $o$ for subject and object, respectively. I leave open how this information is encoded, e.g. by syntactic position, case inflection, or cross reference. I also leave open whether the syntactic function is encoded directly at the NP level, or whether the NP gets (abstract) case from the verb, as assumed in Government and Binding Theory. I simply assume that the information is present at the level of the determiner, which has the category $\mathrm{NP}_{c} / \mathrm{N}$, and hence, at the level of the NP. In the case at hand, we have an indefinite determiner, which is not expressed overtly. Adjuncts like in the kitchen, on the other hand, do not bind an argument of the verb.

Now look at the semantic tree. Verbs are represented as one-place predicates of events. The syntactic arguments have no direct counterpart in the immediate semantic representation of the verbal predicate, e.g. in drink'. Therefore, they must be related to the event by thematic relations such as AG, PAT, IN (agent, patient, interior location). The thematic roles of syntactic arguments like subject and object must be specified in the lexical entry of the verb, whereas with free adjuncts they are specified within the adjunct. ${ }^{7}$

In the case of adjuncts, I just assume that the semantic representation of the adjunct is an operator which is applied to the semantic representation of the event predicate. In the case of arguments, we could assume a semantic representation for verbs like drink as $\lambda \mathrm{x} \lambda \mathrm{y} \lambda \mathrm{e}[\mathbf{d r i n k}(\mathrm{e}) \wedge \mathbf{A G}(\mathrm{e}, \mathrm{y}) \wedge$ $\operatorname{PAT}(\mathrm{e}, \mathrm{x})]$, so that the verb can be applied as a function to its syntactic arguments. But this representation has at least two unwelcome consequences: First, the order of application is fixed by the semantic representation, which is unplausible at least for languages which do not have a rigid word order. Second, the application of the verbal expression to a syntactic argument changes the semantic type of the verbal expression. As the order of application of syntactic arguments and free adjuncts should not be fixed by the semantics in advance, we would have to assume different syntactic types for free adjuncts as well. Furthermore, the characterizing predicates for reference types, as e.g. cumulative and quantized reference, could not be applied directly to event predicates.

Therefore, I prefer another, more flexible representation, which is inspired by unification grammar, namely the use of free variables. I assume some free variables which are assigned in a standard way to syntactic functions; for example, the variable $x_{\mathrm{s}}$ is assigned to the subject and the variable $x_{0}$ is assigned to the object. These variables come in with the interpretation 
of the determiner, whose syntactic category carries the relevant information. $8,9,10$

After all free variables are bound, we obtain a predicate on events without free variables, the sentence radical. This can be transformed to a sentence by the application of a sentence mood operator, e.g. the declarative operator. I assume here that this operator simply binds the event variable with an existential quantifier.

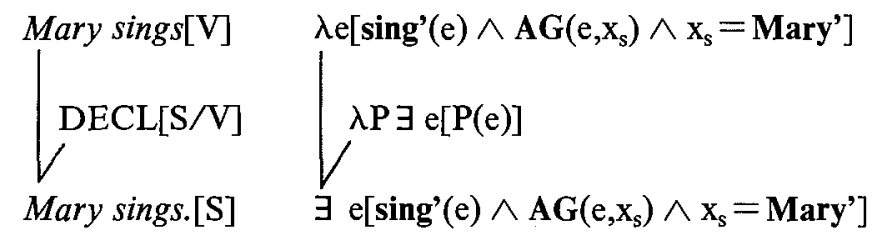

The representation of declarative sentences basically conforms to the truth scheme of Austin (1950) (as discussed in Barwise \& Perry 1983 and Barwise \& Etchemendy 1987), who assumed that a declarative sentence consists of two basic semantic constituents, namely a specification of an event type and a reference to a specific event, which is claimed to be of the specified type. Event types I capture by event predicates, and the reference to a specific event not quite in line with Austin's scheme by the existential quantifier. Surely, both decisions will turn out too simple, but they suffice for the present purpose, and our analysis hopefully can be recast in more complex representations. In section (6) below, I will make this structure more explicit by including reference times in the semantics of the declarative operator.

Up to now, I have said nothing about the nature of events. Events are represented by individuals, and they are characterized by the predicate $\mathbf{E}$, which is supposed to be disjoint from $\mathbf{O}$. I assume that $\mathbf{E}$ is structured like $O$ as a complete complementary join semi-lattice without bottom element.

The intuitive insight that atelic expressions are similar to mass nouns and bare plurals, whereas telic expressions resemble measure constructions and count noun constructions, now can be captured in the formal representation. Basically, telic predicates can be reconstructed as quantized event predicates, and atelic predicates as event predicates which are strictly cumulative (or at least, non-quantized). This corresponds to the fact that, for example, a proper part of an event of recovering will not be considered as an event of recovering, whereas a proper part of an event of walking will be considered as an event of walking in normal cases, except when it is too small to count as walking. Here, the problem of minimal parts raises its head again, another parallelism to the semantics of nominal predicates.

The intuitive distinction between telic and atelic expressions, that the former have a terminal point whereas the latter lack it, is captured in this reconstruction as follows. If we assume a mapping from events to times (cf. section 5), then we can assume that every event e has a terminal time point (the final atomic point of its run time, cf. section 5). That is, we cannot make a distinction between telic and atelic 'events'11. But we can make the distinction at a higher level, at the level of event predicates or types. An event e of type $\phi$ can be said to have a terminal point $t$ relative to $\phi$ iff $t$ is the final temporal point of $e$ and there are no $e^{\prime}$ of type $\phi$ with either $\mathrm{e}^{\prime} C_{\mathrm{E}} \mathrm{e}$ or $\mathrm{e}_{\mathrm{E}} \mathrm{e}^{\prime}$ which have an earlier or a later final temporal point; otherwise, e has no terminal point relative to $\phi$. Note that the function 'is the terminal point of' is two-place; it does not only take an event $\mathrm{e}$, but also a type (an event predicate) $\phi$. That is, a terminal point of an event is a terminal point only under a certain description. This is quite plausible; for example, $t$ might be a terminal point of an event e under the description run three miles, but not under the description run four miles. ${ }^{12}$

I will now show how the influence of the reference types of nominal predicates on the temporal constitution of the verbal predicates can also be captured formally in a semantically well-motivated 'calculus'. The idea is that, with certain thematic re tions, the reference properties of the syntactic arguments carry over to the reference properties of the complex construction. There is a way to visualize this transfer of reference types, namely space-time diagrams. In these diagrams, space is represented by one axis, and time by the other. Objects can be represented as lines, or more correctly as bands, because their spatial extension matters. Events can be mapped to the time axis, which will be captured formally in section (5). Now consider $\mathrm{e}$, the event of drinking a quantity of wine w (which is gradually disappearing during the drinking):

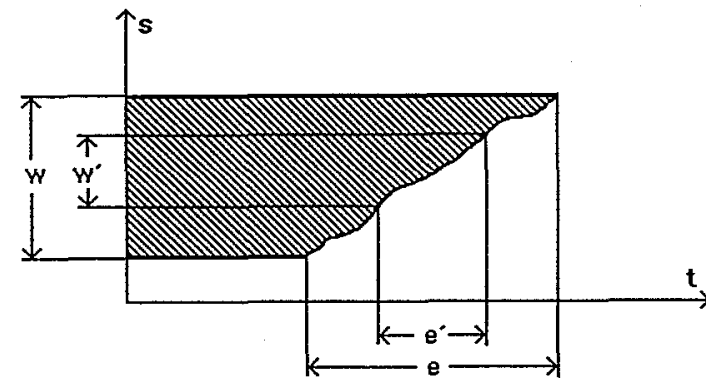


By this picture, idealized though it is, the intuitive notion that the object is subjected to the event in a gradual manner should become clear. Consider two possible descriptions of $w$ and, consequently, e. First, let w be described as wine, and hence e as drink wine. As wine is cumulative, it is normally the case that it can also be applied to proper parts of $w$, like $w^{\prime}$. But then the predicate drink wine should be applicable to the corresponding proper part of e, namely e', as well. Second, let w be described as a glass of wine, and e consequently as drink a glass of wine. As a glass of wine is quantized, no proper part of w can be described with a glass of wine. But then no proper part of e should be describable as drink a glass of wine either.

Technically speaking, we have to assume a homomorphism from objects to events which preserves the lattice structure. Here, I will develop a theory which captures this intuitive notion in terms of plausible transfer properties of thematic relations. To characterize these properties, I assume the following predicates:

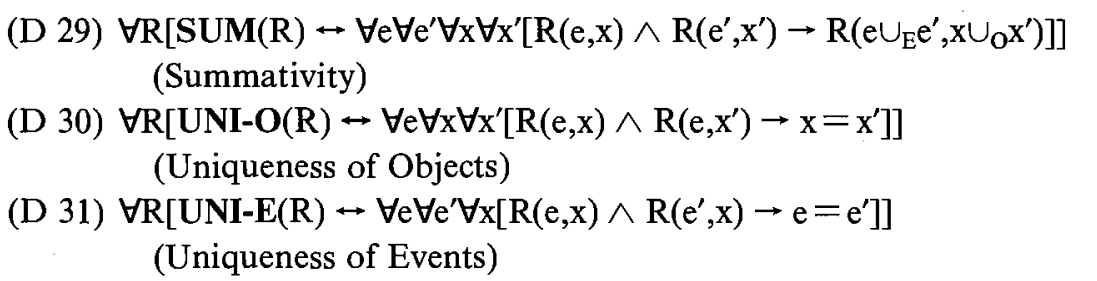

(D 32) $\forall \mathrm{R}\left[\mathrm{MAP}-\mathrm{O}(\mathrm{R}) \rightarrow \forall \mathrm{e} \forall \mathrm{e}^{\prime} \forall \mathrm{x}\left[\mathrm{R}(\mathrm{e}, \mathrm{x}) \wedge \mathrm{e}^{\prime} \subseteq_{\mathrm{E}} \mathrm{e} \rightarrow \exists \mathrm{x}^{\prime}\left[\mathrm{x}^{\prime} \subseteq_{\mathrm{O}} \mathrm{x} \wedge \mathrm{R}\left(\mathrm{e}^{\prime}, \mathrm{x}^{\prime}\right)\right]\right]\right.$ (Mapping to Objects)

(D 33) $\forall \mathrm{R}\left[\mathrm{MAP}-\mathrm{E}(\mathrm{R}) \leftrightarrow \forall \mathrm{e} \forall \mathrm{x} \forall \mathrm{x}^{\prime}\left[\mathrm{R}(\mathrm{e}, \mathrm{x}) \wedge \mathrm{x}^{\prime} \subseteq_{\mathrm{O}} \mathrm{x} \rightarrow \exists \mathrm{e}^{\prime}\left[\mathrm{e}^{\prime} \subseteq_{\mathrm{E}} \mathrm{e} \wedge \mathrm{R}\left(\mathrm{e}^{\prime}, \mathrm{x}^{\prime}\right)\right]\right]\right]$ (Mapping to Events)

Summativity (that is, cumulativity for two-place relations) provides the basic connection between thematic relations and the join operations. For example, two events of drinking a glass of wine yield an event of drinking two glasses of wine. Uniqueness of objects captures the fact that an event is related to a specific object; for example, a drinking of a glass of wine is related only to this glass of wine as patient, and to nothing else. Uniqueness of events says that there is only one event related to the object by the thematic relation; for example, for a specific glass of wine there can be only one drinking event. Mapping to objects means in the example at hand that every part of a drinking of a glass of wine corresponds to a part of the glass of wine. And mapping to events says that every part of the glass of wine being drunken corresponds to a part of the drinking event.
The following postulate covers the notion of iterativity. It is a relation between an event $e$, an object $x$ and a thematic relation $\mathrm{R}$ saying that at least one part of $\mathrm{x}$ is subjected to at least two different parts of $\mathrm{e}$. This applies to, e.g., the reading of a book if at least one part of the book is read twice.

(D 34) $\forall \mathrm{e}, \mathrm{x}, \mathrm{R}[\mathbf{I T E R}(\mathrm{e}, \mathrm{x}, \mathrm{R}) \leftrightarrow \mathrm{R}(\mathrm{e}, \mathrm{x}) \wedge$ $\left.\exists \mathrm{e}^{\prime} \exists \mathrm{e}^{\prime \prime} \exists \mathrm{x}^{\prime}\left[\mathrm{e}^{\prime} \subseteq_{\mathrm{E}} \mathrm{e} \wedge \mathrm{e}^{\prime \prime} \subseteq_{\mathrm{E}} \mathrm{e} \wedge{ }_{7} \mathrm{e}^{\prime}=\mathrm{e}^{\prime \prime} \wedge \mathrm{x}^{\prime} \subseteq_{\mathrm{O}} \mathrm{x} \wedge \mathrm{R}\left(\mathrm{e}^{\prime}, \mathrm{x}^{\prime}\right) \wedge \mathrm{R}\left(\mathrm{e}^{\prime \prime} \mathrm{x}^{\prime}\right)\right]\right]$ (Iterativity)

Now we are ready to investigate which properties we need for thematic relations to capture the transfer of reference properties. Let us assume that an expression like read a letter is translated by predicates $\phi$,

(12) $\phi=\lambda \mathrm{e} \exists \mathrm{x}[\alpha(\mathrm{e}) \wedge \delta(\mathrm{x}) \wedge \theta(\mathrm{e}, \mathrm{x})]$

$$
\text { e.g. read-a-letter }=\lambda e \exists x\left[\operatorname{read}^{\prime}(e) \wedge \text { letter' }^{\prime}(x, 1) \wedge \operatorname{PAT}(e, x)\right]
$$

where $\alpha$ represents the verbal predicate $(r e a d), \delta$ represents the nominal predicate (a letter), and $\theta$ represents a thematic relation (here, a specific patient relation). In the following, I will examine the effects of some properties of $\delta$ and $\theta$ on $\phi$. The verbal predicate $\alpha$ will be considered to be cumulative throughout.

We start with the question: What are the conditions for $\phi$ to be cumulative? Most importantly, $\phi$ is cumulative if $\delta$ is cumulative and $\theta$ is summative (an example is read letters).

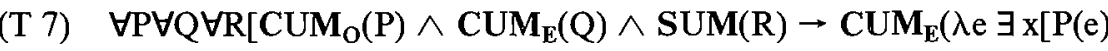 $\wedge \mathrm{Q}(\mathrm{x}) \wedge \mathrm{R}(\mathrm{e}, \mathrm{x})])]$}

Proof: Assume $\mathrm{e}_{1}, \mathrm{e}_{2}$ (not necessarily distinct) with $\phi\left(\mathrm{e}_{1}\right), \phi\left(\mathrm{e}_{2}\right)$. According to the definiton of $\phi$, there are two objects $\mathrm{x}_{1}, \mathrm{x}_{2}$ with $\alpha\left(\mathrm{e}_{1}\right), \delta\left(\mathrm{x}_{1}\right), \theta\left(\mathrm{e}_{1}, \mathrm{x}_{1}\right)$ and $\alpha\left(\mathrm{e}_{2}\right), \delta\left(\mathrm{x}_{2}\right), \theta\left(\mathrm{e}_{2}, \mathrm{x}_{2}\right)$. Because $\alpha$ and $\delta$ are cumulative, it holds that $\alpha\left(\mathrm{e}_{1} \cup_{\mathrm{E}} \mathrm{e}_{2}\right)$ and $\delta\left(\mathrm{x}_{1} \cup_{0} \mathrm{x}_{2}\right)$, and because $\theta$ is summative, it holds that $\theta\left(e_{1} \cup_{E} e_{2}, x_{1} \cup \cup_{O} x_{2}\right)$. Hence $\phi\left(e_{1} \cup_{E} e_{2}\right)$, that is, $\phi$ is cumulative.

Although we have not introduced definite noun phrases (see section 7 for their treatment), let us assume that a definite noun phrase is represented by a predicate with singular reference, for example let the letter be a predicate which applies to exactly one letter. As singular predicates are cumulative, albeit in a somewhat pathological way, (T 7) holds for them as well. 


\section{read the letter $\lambda \mathrm{e} \exists \mathrm{x}_{\mathrm{o}}\left[\right.$ read'(e) $\wedge \mathrm{AG}\left(\mathrm{e}, \mathrm{x}_{\mathrm{s}}\right) \wedge \operatorname{PAT}\left(\mathrm{e}, \mathrm{x}_{\mathrm{o}}\right) \wedge$ the- letter' $\left.\left(x_{0}\right)\right]$}

But if we want to understand read the letter as an atelic predicate, as in he read the letter for an hour, then we clearly have to assume either a partitive reading or an iterative reading. For partitive readings see Krifka (1986). As for the iterative reading, it can be shown that if $\phi$ is strictly cumulative, $\theta$ is summative, and $\delta$ has singular reference, then we get an iterative interpretation:

\section{(T 8) $\quad \forall P \forall R \forall e \forall x[S N G$ (P) $\wedge \mathbf{S U M}(\mathrm{R}) \wedge P(e) \wedge R(e, x) \wedge$ $\left.\left.\operatorname{SCUM}_{\mathrm{E}}(\lambda \mathrm{e}] \mathrm{x}[\mathrm{P}(\mathrm{x}) \wedge \mathrm{R}(\mathrm{e}, \mathrm{x})]\right) \rightarrow \operatorname{ITER}(\mathrm{e}, \mathrm{x}, \mathrm{R})\right]$}

Proof: If $\phi$ is strictly cumulative, then we have two distinct $e_{1}, e_{2}$ with $\phi\left(\mathrm{e}_{1}\right), \phi\left(\mathrm{e}_{2}\right)$. According to the definiton of $\phi$, there are two objects $\mathrm{x}_{1}$, $\mathrm{x}_{2}$ with $\delta\left(\mathrm{x}_{1}\right), \theta\left(\mathrm{e}_{1}, \mathrm{x}_{1}\right)$ and $\delta\left(\mathrm{x}_{2}\right), \theta\left(\mathrm{e}_{2}, \mathrm{x}_{2}\right)$. Because $\theta$ is summative, it holds that $\theta\left(e_{1} \cup_{E} e_{2}, x_{1} \cup_{O} x_{2}\right)$, and because $\delta$ has singular reference, it holds that $\mathrm{x}_{1}=\mathrm{x}_{2}$. With $\theta\left(\mathrm{e}_{1} \cup_{\mathrm{E}} \mathrm{e}_{2}, \mathrm{x}_{1}\right), \theta\left(\mathrm{e}_{1}, \mathrm{x}_{1}\right), \theta\left(\mathrm{e}_{2}, \mathrm{x}_{1}\right)$ and $\textrm{e}_{1}=\mathrm{e}_{2}$, the conditions for iterativity (D 34) are met, as $x_{1}$ is subjected to two different parts of the event $e_{1} \cup_{E} e_{2}$, for example $e_{1}$ and $e_{2}$.

On the other hand, if we exlude the iterative interpretation and retain singular reference of $\delta$ and summativity of $\theta$, then it follows by modus tollens that $\phi$ cannot be strictly cumulative:

(T 9) $\forall \mathrm{P} \forall \mathrm{R} \forall \mathrm{e} \forall \mathrm{x}\left[\mathrm{SNG}_{\mathrm{O}}(\mathrm{P}) \wedge \mathrm{SUM}(\mathrm{R}) \wedge \mathrm{P}(\mathrm{e}) \wedge \mathrm{R}(\mathrm{e}, \mathrm{x}) \wedge \neg \mathrm{ITER}(\mathrm{e}, \mathrm{x}, \mathrm{R})\right.$ $\left.\rightarrow{ }_{\neg} \operatorname{SCUM}_{\mathrm{E}}(\lambda \mathrm{e} \exists \mathrm{x}[\mathrm{P}(\mathrm{x}) \wedge \mathrm{R}(\mathrm{e}, \mathrm{x})])\right]$

In some cases the iterative interpretation is excluded in the first place, namely with effected or consumed objects, as in write the letter or drink the wine. The reason is that an object can be subjected to an event of drinking or writing a maximum of one time in its career. Therefore, uniqueness of events should be postulated for the respective thematic relations. ${ }^{13}$ And this excludes an iterative interpretation in the first place.

\section{(T 10) $\forall \mathrm{R} \forall \mathrm{e} \forall \mathrm{x}[\mathrm{R}(\mathrm{e}, \mathrm{x}) \wedge \mathrm{UNI}-\mathrm{E}(\mathrm{R}) \rightarrow \neg \operatorname{ITER}(\mathrm{e}, \mathrm{x}, \mathrm{R})]$}

Proof: Assume to the contrary that $\theta$ is unique for events, $\theta\left(\mathrm{e}_{0}, \mathrm{x}_{0}\right)$ and $\operatorname{ITER}\left(\mathrm{e}_{0}, \mathrm{x}_{0}, \theta\right)$. Because of iterativity, it follows that there are $\dot{e}_{1}, \mathrm{e}_{2}, \mathrm{x}_{1}$ with $\mathrm{e}_{1} \subset_{\mathrm{E}} \mathrm{e}_{0}, \mathrm{e}_{2} \subset_{\mathrm{E}} \mathrm{e}_{0}, \neg \mathrm{e}_{1}=\mathrm{e}_{2}$ and $\mathrm{x}_{1} \subset_{\mathrm{O}} \mathrm{x}_{0}$ for which it holds that $\theta\left(\mathrm{e}_{1}, \mathrm{x}_{1}\right)$ and $\theta\left(e_{2}, x_{1}\right)$. But this contradicts uniqueness of events.
Let us now examine the influence of quantized nominal predicates like a letter. Under which conditions can we assume that they cause the complex verbal predicate to be quantized as well? One set of conditions is that the thematic role $\theta$ must satisfy uniqueness of objects and mapping to objects, and that iterative interpretations are excluded.

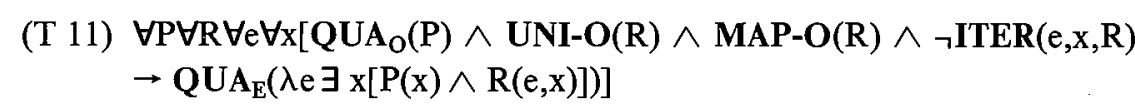

Proof: We assume to the contrary that $\delta$ is quantized, $\phi\left(\mathrm{e}_{1}\right), \phi\left(\mathrm{e}_{2}\right)$ and $\mathrm{e}_{2} C_{\mathrm{E}} \mathrm{e}_{1}$. Then there are $\mathrm{x}_{1}, \mathrm{x}_{2}$ with $\delta\left(\mathrm{x}_{1}\right), \theta\left(\mathrm{e}_{1}, \mathrm{x}_{1}\right)$ and $\delta\left(\mathrm{x}_{2}\right), \theta\left(\mathrm{e}_{2}, \mathrm{x}_{2}\right)$, according to the definition of $\phi$. Because $e_{2} \subset_{E} e_{1}$ and $\theta$ satisfies mapping to objects, there is an $x_{3}$ such that $x_{3} \subseteq_{0} x_{1}$ and $\theta\left(e_{2}, x_{3}\right)$. Because of uniqueness of objects, it holds that $x_{3}=x_{2}$, and therefore $x_{2} \subseteq_{0} x_{1}$. As we have $\theta\left(e_{2}, x_{2}\right)$, $\mathrm{e}_{2} \subset_{\mathrm{E}} \mathrm{e}_{1}$ and ${ }_{\neg} \operatorname{ITER}\left(\mathrm{e}_{1}, \mathrm{x}_{1}, \theta\right)$, we can infer that $\neg \mathrm{x}_{1}=\mathrm{x}_{2}$. With $\mathrm{x}_{2} \subseteq_{\mathrm{O}} \mathrm{x}_{1}$, this yields $\mathrm{x}_{2} \subset_{0} \mathrm{x}_{1}$, which contradicts the assumption that $\delta$ is quantized. Hence there are no $e_{1}, e_{2}$ as assumed above, and that means that $\phi$ is quantized.

As a special case of (T 11), we have the following theorem for thematic relations which satisfy uniqueness of events (e.g. effected and consumed objects), as this property excludes an iterative interpretation in the first place according to (T 10).

\section{$\left(\mathrm{T}\right.$ 12) $\forall \mathrm{P} \lambda \mathrm{R}\left[\mathrm{QUA} \mathrm{A}_{\mathrm{O}}(\mathrm{P}) \wedge \mathrm{UNI}-\mathrm{O}(\mathrm{R}) \wedge \mathrm{MAP}-\mathrm{O}(\mathrm{R}) \wedge \mathrm{UNI}-\mathrm{E}(\theta) \rightarrow\right.$ $\left.\mathbf{Q U A}_{\mathrm{E}}(\lambda \mathrm{e} \exists \mathrm{x}[\mathrm{P}(\mathrm{x}) \wedge \mathrm{R}(\mathrm{e}, \mathrm{x})])\right]$}

Even in the iterative case it holds that predicates like read a letter are atomic, as the respective events are composed of non-iterative parts. The conditions for thematic relations which are relevant to reach this result are that they satisfy uniqueness of objects and mapping to events. With our postulates, we have to assume $\delta$ not only to be quantized, but to be strictly quantized, which is not a substantial limitation.

\section{$\left(\mathrm{T}\right.$ 13) $\forall \mathrm{P} \lambda \mathrm{R}\left[\mathrm{SQUA} \mathrm{A}_{\mathrm{O}}(\mathrm{P}) \wedge \mathrm{MAP}-\mathrm{E}(\mathrm{R}) \wedge \mathrm{UNI}-\mathrm{O}(\mathrm{R}) \rightarrow \mathrm{ATM}_{\mathrm{E}}(\lambda \mathrm{e} \exists \mathrm{x}[\mathrm{P}(\mathrm{x})\right.$ $\wedge \mathrm{R}(\mathrm{e}, \mathrm{x})])]$}

Proof: Assume an $\mathrm{e}_{1}$ with $\phi\left(\mathrm{e}_{1}\right)$, hence an $\mathrm{x}_{1}$ with $\delta\left(\mathrm{x}_{1}\right)$ and $\theta\left(\mathrm{e}_{1}, \mathrm{x}_{1}\right)$. Because $\delta$ is strictly quantized, $x_{1}$ contains a proper part $x_{2}$, that is, $x_{2} \subset_{0} x_{1}$, with $\neg \delta\left(\mathrm{x}_{2}\right)$. Because of mapping to events, there is an $\mathrm{e}_{2}$ with $\mathrm{e}_{2} \complement_{\mathrm{E}} \mathrm{e}_{1}$ and $\theta\left(\mathrm{e}_{2}, \mathrm{x}_{2}\right)$. Because of uniqueness of objects, $x_{2}$ is the only object with this property. Hence there is no $\mathrm{x}$ with $\delta(\mathrm{x})$ and $\theta\left(\mathrm{e}_{2}, \mathrm{x}\right)$. But then $\neg \phi\left(\mathrm{e}_{2}\right)$ holds, and 
this means that $\mathrm{e}_{1}$ contains an $\phi$-atom. As we made no special assumption for $e_{1}$, it follows that $\phi$ is atomic (cf. D 18).

To conclude this section, let us look at the patient relations we have to assume for different classes of verbs. First, I introduce a new notion, called graduality. It comprises uniqueness of objects, mapping to objects, and mapping to events and says intuitively that the object is subjected to the event in a gradual or incremental manner, that is, in the way visualized by the space-time diagramm (11).

\section{(D 35) $\forall$ R[GRAD(R) $\leftrightarrow$ UNI-O(R) $\wedge$ MAP-O(R) $\wedge$ MAP-E(R) $]$ (Graduality)}

The criteria for the classification of thematic roles can be applied to transitive verbs. This yields at least three interesting classes; two of them can be further subdivided for independent reasons.

\section{example SUM GRAD UNI-E label}

\begin{tabular}{lllll}
\hline write a letter & $\mathrm{X}$ & $\mathrm{X}$ & $\mathrm{X}$ & gradual effected patient \\
eat an apple & $\mathrm{X}$ & $\mathrm{X}$ & $\mathrm{X}$ & gradual consumed patient \\
read a letter & $\mathrm{X}$ & $\mathrm{X}$ & - & gradual patient \\
touch a cat & $\mathrm{X}$ & - & - & affected patient \\
see a horse & $\mathrm{X}$ & - & - & stimulus
\end{tabular}

\section{TEMPORAL ADVERBIALS}

In this section, I want to show why durative adverbials like for an hour and time-span adverbials like in an hour provide diagnostic contexts for the temporal constitution. To do this, I have to introduce times into the model structure.

I assume a predicate $\mathbf{T}$, extensionally disjunct from $\mathbf{O}$ and $\mathbf{E}$, which characterizes times and carries a complementary complete join semi-lattice without bottom element. In addition, I assume that this lattice is atomic, with $\mathbf{T}_{\mathbf{a}}$ as the set of $\mathbf{T}$-atoms; the atoms will represent time points. The variables which range over the extension of $T$ will be given as $t$, $t$, etc.

\section{(D 36) $\forall t\left[T_{a}(t) \leftrightarrow \operatorname{ATOM}_{T}(t, T)\right]$}

Furthermore, I assume a relation of temporal precedence. Let $\mathbf{T}_{\mathbf{a}}$ be linearly ordered by a transitive relation $<_{\mathrm{T}}$ (D 37). This relation can be extended to times in general by saying that a time $t$ temporally precedes a time $t^{\prime}$ if every part of $t$ precedes every part of $t^{\prime}$ (D 38). With this, we can define convex times, or time intervals (D 39).

(D 37) $\forall \mathrm{t} \forall \mathrm{t}^{\prime} \forall \mathrm{t}^{\prime \prime}\left[\mathrm{T}_{\mathrm{a}}(\mathrm{t}) \wedge \mathrm{T}_{\mathrm{a}}\left(\mathrm{t}^{\prime}\right) \wedge \mathrm{T}_{\mathrm{a}}\left(\mathrm{t}^{\prime \prime}\right) \rightarrow \neg_{\mathrm{t}}<_{\mathrm{T}} \mathrm{t} \wedge\left[\mathrm{t}<{ }_{\mathrm{T}} \mathrm{t}^{\prime} \wedge \mathrm{t}^{\prime}<_{\mathrm{T}} \mathrm{t}^{\prime \prime} \rightarrow \mathrm{t}<_{\mathrm{T}} \mathrm{t}^{\prime \prime}\right]\right]$ (D 38) $\forall \mathrm{t} \forall \mathrm{t}^{\prime}\left[\mathrm{t}<_{\mathrm{T}} \mathrm{t}^{\prime} \rightarrow \forall \mathrm{t}^{\prime \prime} \forall \mathrm{t}^{\prime \prime \prime}\left[\mathrm{T}_{\mathrm{a}}\left(\mathrm{t}^{\prime \prime}\right) \wedge \mathrm{T}_{\mathrm{a}}\left(\mathrm{t}^{\prime \prime \prime}\right) \wedge \mathrm{t}^{\prime \prime} \subseteq_{\mathrm{T}} \mathrm{t} \wedge \mathrm{t}^{\prime \prime \prime} \subseteq_{\mathrm{T}} \mathrm{t}^{\prime} \rightarrow \mathrm{t}^{\prime \prime}<_{\mathrm{T}} \mathrm{t}^{\prime \prime \prime}\right]\right]$ (D 39) $\forall \mathrm{t}\left[\mathrm{CONV}(\mathrm{t}) \rightarrow \forall \mathrm{t}^{\prime} \forall \mathrm{t}^{\prime \prime} \forall \mathrm{t}^{\prime \prime \prime}\left[\mathrm{t}^{\prime} \complement_{\mathrm{T}} \mathrm{t} \wedge \mathrm{t}^{\prime \prime} \subseteq_{\mathrm{T}} \mathrm{t} \wedge \mathrm{t}^{\prime}<_{\mathrm{T}} \mathrm{t}^{\prime \prime \prime}<_{\mathrm{T}} \mathrm{t}^{\prime \prime} \rightarrow \mathrm{t}^{\prime \prime \prime} \subseteq_{\mathrm{T}} \mathrm{t}\right]\right]$

I further assume a function $\tau$ from $\mathbf{E}$ to into the extension of $\mathbf{T}$, the temporal trace function. This function maps an event to its temporal trace, or "run time'. It is a homomorphism relative to the joins:

(D 40) $\forall \mathrm{e} \forall \mathrm{e}^{\prime}\left[\tau(\mathrm{e}) \cup_{\mathrm{T}} \tau\left(\mathrm{e}^{\prime}\right)=\tau\left(\mathrm{e}_{\mathrm{E}} \mathrm{e}^{\prime}\right)\right]$

We start with durative adverbials. They can be considered as the adverbial counterpart to measure phrases (cf. section 3 ). They differ from adnominal measure phrases insofar as there seem to be no measure functions which can be applied to events directly, but only measure functions which can be applied to entities which bear a relation to events, most notably times (as in sing for an hour). This relation is modelled by the temporal trace function $\tau$. Assume an extensive measure function for times $\mu, \mathbf{E M F}_{\mathbf{T}}$ ( $\precsim \mu$, $\left.t_{\mu}, \mu\right)$. Then we can construe a derived measure function $\mu^{\prime}$ for events as in (D 41). It can be shown that $\mu^{\prime}$ is extensive relative to some preorder ${ }_{\mu^{\prime}}$ and concatenation $+_{\mu^{\prime}}$ for events which are defined as in (D 42) and (D 43), that is, $\mathbf{E M F}_{\mathrm{E}}\left(\precsim_{\mu^{\prime}},+_{\mu^{\prime}}, \mu^{\prime}\right)$.

(D 41) $\forall \mathrm{e}\left[\mu^{\prime}(\mathrm{e})=\mu(\tau(\mathrm{e}))\right]$

(D 42) $\forall \mathrm{e} \forall \mathrm{e}^{\prime}\left[\tau(\mathrm{e}) \precsim_{\mu} \tau\left(\mathrm{e}^{\prime}\right) \rightarrow \mathrm{e} \precsim_{\mu}, \mathrm{e}^{\prime}\right]$

(D 43) $\forall \mathrm{e} \forall \mathrm{e}^{\prime}\left[\neg \tau(\mathrm{e})^{\circ}{ }_{\mathrm{T}} \tau\left(\mathrm{e}^{\prime}\right) \leftrightarrow\left[\mathrm{e}{ }_{\mu^{\prime}} \mathrm{e}^{\prime}=\mathrm{e} \cup_{\mathrm{E}} \mathrm{e}^{\prime}\right]\right]$

The restriction that $e_{1}$ and $e_{2}$ must not overlap temporally captures the most prominent interpretation. Consider the fact that, for example, John sang from 2 o'clock to 4 o'clock, and Mary sang from 3 o'clock to 5 o'clock. Then it holds either that John and Mary sang for 2 hours (distributively) or that John and Mary sang for 3 hours (collectively), but it does not hold that John and Mary sang for 4 hours. ${ }^{14}$

As an example for durative adverbials, assume that $\mathbf{h}$ ' represents hour, an extensive measure function for events. If we analyze durative adverbials as the adverbial counterpart of measure phrases, we arrive at interpretations like the following one: 
(15)

$$
\begin{aligned}
& \text { for an hour } \\
& \lambda \mathrm{P} \forall \mathrm{e}\left[\mathrm{P}(\mathrm{e}) \wedge \mathrm{h}^{\prime}(\mathrm{e})=1 / \mathrm{QMOD}_{\mathrm{E}}\left(\mathrm{P}, \lambda \mathrm{P} \lambda \mathrm{e}\left[\mathrm{P}(\mathrm{e}) \wedge \mathbf{h}^{\prime}(\mathrm{e})=1\right]\right)\right]
\end{aligned}
$$

The wellformedness condition after "/" excludes quantized predicates $\mathrm{P}$ and says that the result of the application of the modifier to an event predicate must result in a quantized event predicate (cf. D 28). Thus, the data in $(1,2)$ are explained.

It is worth noting that durative adverbials are downward entailing in our analysis; e.g. Ann read for $n$ hours implies Ann read for $n^{\prime}$ hours if $\mathrm{n}^{\prime}<\mathrm{n}$. Therefore, a situation for which Ann read for three hours is true is also a situation for which Ann read for two hours is true. But the second sentence can be shown to be less informative than the first one. Therefore, if both sentences are true, the first one is preferred by the pragmatic rule I which was stated in section (3) above.

I now turn to time-span adverbials like in an hour. The semantics of these adverbial modifiers can be characterized as follows: They say that an event is located in a convex time with a given length. Note that this captures the fact that these adverbials are expressed by the preposition in. As an example, consider the following.

$$
\text { in an hour } \lambda \mathrm{P} \lambda \mathrm{e}\left[\mathrm{P}(\mathrm{e}) \wedge \exists \mathrm{t}\left[\operatorname{CONV}(\mathrm{t}) \wedge \mathrm{h}^{\prime}(\mathrm{t})=1 \wedge \tau(\mathrm{e}) \mathcal{\complement}_{\mathrm{T}} \mathrm{t}\right]\right]
$$

Why have time-span adverbials, then, the well-known effects with telic and atelic verbal predicates (cf. 1,2)? The reason is to be found in pragmatics. I will start to outline the argument informally. First, note that time-span adverbials are upward-entailing operators. Consider for example drink a glass of wine in $n$ hour(s). If this predicate can be applied to an event, then the predicate drink a glass of wine in $n^{\prime}$. hour $(s)$, with $\mathrm{n}^{\prime}>\mathrm{n}$, can be applied to this event as well. This is obvious if one considers examples like (17), which are exactly parallel to the standard examples of scalar implications (18):

(17) Ann drank a bottle of wine in one hour; in fact, she did it in 53 minutes.

(18) Ann earns 4000 DM; in fact, she earns 4300 DM.

This upward entailing property of time-span adverbials predicts their combinatorial behaviour in $(1,2)$. If one has a sentence pattern like drink $\delta$ in $n$ hour(s), the pragmatic rule (I) I stated in section (3) forces the value of $\mathbf{n}$ to be as small as possible, in order to be maximally informative. But $\mathrm{n}$ can have a smallest value only if the predicate $\operatorname{drink} \delta$ is atomic; otherwise it is possible to take smaller and smaller events which still fall under drink $\delta$. Now, if $\delta$ is quantized, then the predicate drink $\delta$ is atomic; this we showed in (T 13). On the other hand, if $\delta$ is not quantized, then the atomicity depends on the position we take towards the minimal part problem. Normally, natural language refrains from referring to minimal parts of cumulative predicates, be it mass nouns, bare plurals, or atelic verbal predicates. But it is exactly in contexts like this that we find examples like (19), which can be read as report of some unusual competition. They can be explained if one assumes that atomic drinking. events are referred to.

\section{(19) Ann drank wine in 0.43 seconds.}

Thus, it is not quantization, but more generally atomicity of the verbal predicate which is required by time-span adverbials.

The contrast between drink wine in 0.43 seconds and *drink wine in an hour shows that we should not look for a purely semantic anomaly in the latter case, but for a pragmatic one. I will assume that expressions like *drink wine in an hour cannot be reasonably construed as referring to minimal events of drinking an hour is just too long for that. But then, the application of the time-span adverbial does not lead to a more specific meaning and is, therefore, redundant. The pragmatic rule which is at work here can be directly inferred from Grice's maxim of manner, 'Be brief!'.

\section{Pragmatic Rule II:}

If two expressions are equally informative, and one is more complex than the other, then choose the one which is less complex.

The steps in this argument can be explicated formally in our representation of time-span adverbials. Consider the following phrase, where $\alpha$ is a verbal predicate, $\mu$ an extensive measure function, and $v$ a number.

$$
\text { (20) } \phi=\lambda \mathrm{e}\left[\alpha(\mathrm{e}) \wedge \exists \mathrm{t}\left[\mu(\mathrm{t})=v \wedge \operatorname{CONV}(\mathrm{t}) \wedge \tau(\mathrm{e}) \subseteq_{\mathrm{E}} \mathrm{t}\right]\right]
$$

First, it can be proved under some additional assumptions that time-span adverbials are upward-entailing.

Sketch of the proof: Assume an $e_{1}$ with $\phi\left(e_{1}\right)$. Then there is a $t_{1}$ with $\mu\left(\mathrm{t}_{1}\right)=v$ and $\tau\left(\mathrm{e}_{1}\right) \subset_{\mathrm{T}} \mathrm{t}_{1}$. Assume a number $v^{\prime}$, with $v \leqslant v^{\prime}$, and assume that 
there is a $t_{2}$ with $\operatorname{CONV}\left(\mathrm{t}_{2}\right), \mu\left(\mathrm{t}_{2}\right)=v^{\prime}$, and $\mathrm{t}_{1} \subseteq_{\mathrm{T}} \mathrm{t}_{2}$. (This is fairly uncontroversial in our context. One has to presuppose e.g. that times are as dense as the set of numbers from which $v, v^{\prime}$ are taken.) But then it holds that $\tau\left(\mathrm{e}_{1}\right) \subseteq_{\mathrm{T}} \mathrm{t}_{2}$ because the $\varsigma_{\mathrm{T}}$-relation is transitive, and consequently that $\phi\left[v / v^{\prime}\right]\left(\mathrm{e}_{1}\right)$, where $\phi\left[v / v^{\prime}\right]$ is equal to $\phi$ with the exception that $v$ is replaced by $v^{\prime}$. Therefore, $\phi$ is upward entailing with respect to $v$.

Second, we have to show that if $\alpha$ is atomic, then we have smallest convex times $\mathrm{t}$ for which $\exists \mathrm{e}\left[\alpha(\mathrm{e}) \wedge \tau(\mathrm{e}) \underline{\mathrm{T}}_{\mathrm{T}} \mathrm{t}\right]$ holds.

Sketch of the proof: Assume $\operatorname{ATM}_{\mathrm{E}}(\boldsymbol{\alpha})$, and an $\mathrm{e}_{0}$ with $\alpha\left(\mathrm{e}_{0}\right)$. Then for every $\alpha$-partition of e into smaller parts, that is, for every $\mathrm{e}_{1}, \ldots, \mathrm{e}_{\mathrm{k}}$ with $\alpha\left(e_{1}\right), . ., \alpha\left(e_{k}\right)$ and $\left.e_{0}=e_{1} \cup_{E} e_{2} \cup_{E} . . \cup_{E} e_{k}\right)$, it holds that for every $e_{i}, 1 \leqslant i \leqslant k$, there is an e with $\operatorname{ATOM}_{\mathrm{E}}(\mathrm{e}, \alpha)$ and $\mathrm{e} \subseteq_{\mathrm{E}} \mathrm{e}_{\mathrm{i}}$. That is, with every element $e_{i}$ in every $\alpha$-partition of $e_{0}$, if one tries to pass over to an $e_{i}^{\prime}$ with $e_{i}^{\prime} C_{E} e_{i}$ and $\alpha\left(\mathrm{e}_{\mathrm{i}}{ }^{\prime}\right)$, one eventually reaches an $\mathrm{e}_{\mathrm{j}}$ for which this is not possible anymore, since $e_{j}$ is an $\alpha$-atom. Those $e_{j}$ are mapped by $\tau$ to times $t_{j}: t_{j}=\tau\left(e_{j}\right)$. Every time $t_{\mathrm{j}}$, in turn, can be mapped to a smallest possible convex time $t_{j}^{\prime}$ with $t_{j} \subseteq_{T} t_{j}^{\prime}$. The smallest convex time $t_{j}^{\prime}$ is the one we are looking for.

If, on the other hand, $\alpha$ is not atomic, then there is an infinite sequence of events $\mathrm{e}_{0}, \mathrm{e}_{1}, .$. with $\mathrm{e}_{\mathrm{i}-1} \subset_{\mathrm{E}} \mathrm{e}_{\mathrm{i}}$ and $\alpha\left(\mathrm{e}_{\mathrm{i}}\right)$ for $\mathrm{i} \geq 0$. Corresponding to this sequence there is a sequence of times $t_{0}, t_{1}, \ldots$ with $t_{i}=\tau\left(e_{i}\right)$ for $i \geq 0$. As $\tau$ is a homomorphism, it holds that $t_{i-1} \subseteq_{T} t_{i}$ for $i \geq 0$. The $t_{i}$ are lower bounds for convex times $t_{i}{ }^{\prime}$ with $t_{i} \subseteq_{T} t_{i}$. As there possibly is no minimal $t_{i}$, it is possible that there is no minimal $\mathbf{t}_{\mathbf{i}}^{\prime}$ either.

\section{NEGATION}

In this and the next section, I will propose a treatment for two topics which have been considered particularly difficult for event semantics: negation and, more generally, quantification. This treatment makes essential use of the event lattice structure.

Negation is a complicated matter for semantic approaches based on events, situations or similar entities. The reason is that negated expressions are not persistent, that is, they can switch their truth value if increasingly larger situations are taken into account. For example, nobody applauded can be true in a certain situation (say, on the right side of the parliament), but false in a larger situation (say, if we we look at the parliament as a whole).

To handle negation correctly, one has to take into account situations which are 'large' enough. One possibility would be to move right to the propositional level and assume that negation is a sentential operator which applies only to propositions and not to event predicates (cf. Bäuerle 1987). But this would imply that negation always has wide scope over event predicate modifiers. If we want to have a uniform analysis of time adverbials like for two hours, this would surely be undesirable. There are examples like the following one, which has a reading in which the durative adverbial has scope over negation: ${ }^{15}$

\section{(21) John didn't laugh for two hours.}

As we have lattices as model structures, we need not leave the event level to get 'large' reference structures. Instead, we can characterize negated expressions with the help of maximal events, that is, the fusion of all events at a certain time. For example, John didn't laugh as an event predicate can be analyzed as referring to maximal events which do not contain an event of John's laughing.

The crucial notions of the maximal event of a specific time and a maximal event of some time can be defined as follows:

(D 44) $\forall \mathrm{e} \forall \mathrm{t}\left[\mathbf{M X T}(\mathrm{e}, \mathrm{t}) \nrightarrow \mathrm{e}=\mathbf{F U}_{\mathrm{E}}\left(\lambda \mathrm{e}\left[\tau(\mathrm{e}) \varsigma_{\mathrm{T}} \mathrm{t}\right]\right)\right]$ (maximal event at time $t$ )

(D 45) $\forall \mathrm{e}\left[\mathrm{MXE}(\mathrm{e}) \leftrightarrow \exists \mathrm{t}\left[\mathrm{e}=\mathbf{F U}_{\mathrm{E}}\left(\lambda \mathrm{e}\left[\tau(\mathrm{e}) \subseteq_{\mathrm{T}} \mathrm{t}\right]\right)\right]\right]$ (maximal events at some time)

The event predicate negation then can be defined as a modifier $\lambda \mathrm{P} \lambda \mathrm{e}[\mathrm{MXE}(\mathrm{e})$ $\left.\wedge \neg \exists \mathrm{e}^{\prime}\left[\mathrm{P}\left(\mathrm{e}^{\prime}\right) \wedge \mathrm{e}^{\prime} \subset_{\mathrm{E}} \mathrm{e}\right]\right]$. As an example, consider the following ${ }^{16}$ :
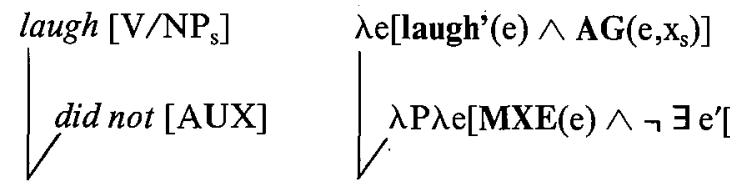
$\left.\wedge \mathrm{e}^{\prime} \subset_{\mathrm{E}} \mathrm{e}\right] \wedge \mathrm{x}_{\mathrm{s}}=$ John'] $(=-\phi$, for short $)$ 
That is, $-\phi$ applies to maximal events which do not contain a laughing by John (see Humberstone 1979, van Benthem 1983 for a related treatment of negation in interval semantics).

It is clear that $-\phi$ is not quantized. For if an event e does not contain an event of a class $\phi$, then no subevent $e^{\prime}$ of e can contain an event of class $\phi$ either; if it did, this property would have been projected from $\mathrm{e}^{\prime}$ to $\mathrm{e}$ because of transitivity of the part-relation. ${ }^{17}$ This explains why they can be combined with durative adverbials, as the wellformedness condition expressed by $\mathbf{Q M O D}_{\mathrm{E}}$ is satisfied. Look at the following possible continuation of the above representation:

(23)

$$
\begin{aligned}
& \text { John did not laugh }[\mathrm{V}]-\phi \\
& \text { for two hours }[\mathrm{PP}] \quad \mid \lambda \mathrm{P} \lambda \mathrm{e}\left[\mathrm{P}(\mathrm{e}) \wedge \mathrm{h}^{\prime}(\mathrm{e})=2 \wedge\right. \\
& \text { / } \\
& \text { John did not laugh } \quad \lambda \mathrm{e}[-\boldsymbol{\phi}] \wedge \mathbf{h}^{\prime}(\mathrm{e})=2 \wedge \\
& \text { for two hours } \left.[\mathrm{V}] \quad \mathbf{Q M O D}_{\mathrm{E}}\left(-\phi, \lambda \mathrm{P} \lambda \mathrm{e}\left[\mathrm{P}(\mathrm{e}) \wedge \mathbf{h}^{\prime}(\mathrm{e})=2\right]\right)\right]
\end{aligned}
$$

Note especially that we did not make any assumptions that the basic predicate $\phi$ is cumulative or quantized. This explains the acceptability of sentences like (24):

\section{(24) John did not drink (a glass of) wine for two days.}

But negation is not only a 'plug' for the temporal constitution of the basic predicate. Surprisingly enough, negation blurs the complementary distribution of durative adverbials and time-span adverbials, as shown by (25).

\section{(25) John did not drink (a glass of) wine in two days.}

It seems that our theory makes a false prediction here, as negated event predicates cannot be considered to be atomic, which we assumed to be a precondition for the application of time-span adverbials. But note that we had to do pragmatic reasoning in order to explain in which cases timespan adverbials are applicable. We said that in order to be maximally informative, the time span must be as small as possible. If we look at examples like (25), we find that pragmatic implications are reversed: the longer the time spans are, the more informative they become. The reason for this is that negation induces an implication reversal (cf. Fauconnier

1978). Therefore, time-span adverbials are appropriate which denote as large an interval as is possible, in order to maximize informativeness. This explains why time-span adverbials can be applied to negated event sentences.

How can a simple negated sentence like John did not laugh be treated along these lines? It is well known that negated sentences must be interpreted relative to a specific reference time. For example, a sentence like John didn't laugh does not mean that John has never laughed, but that John didn't laugh at a certain relevant time. This was observed and discussed first by Partee (1973) with examples like (26.a). Another example is (26.b), where the sentence nobody laughed clearly is to be interpreted with respect to a reference time which is shifted forward with each sentence.

\section{(26) a. I didn't turn off the stove.}

b. John told a joke. Nobody laughed. John told a second joke. Nobody laughed. John told a third joke. Someone yawned.

Bäuerle (1979) argued that sentences in general have to be evaluated with respect to a reference time, which he conceived as a temporal interval. For example, a sentence like John laughed does not mean that John laughed at some time, but that he laughed at a specific time.

Let us assume that every sentence is evaluated at a reference time denoted by the standard time variable $t_{r}$, and that this variable is introduced at the level of the declarative operator. Now there is a basic difference between negated and unnegated sentences: A negated sentence should be true if the run time of its event equals the reference time, whereas an un-negated sentence should be true if the run time of its event is included in the reference time. For example, assume that a temporal adverbial like yesterday can specify the reference time. A sentence like John didn't laugh yesterday intuitively is true only if the non-laughing by John lasted the whole day, whereas for a sentence like John did laugh yesterday, it is not necessary that the laughing of John lasted the whole day.

A way to handle this problem is to assume the weaker inclusion relation as basic and make the negation operator dependent on the reference time. That is, we have the following interpretations of the declarative operator and the negation operator:

$\mathrm{DECL}[\mathrm{S} / \mathrm{V}]$

(28) does not [AUX]

$$
\lambda \mathrm{P} \exists \mathrm{e}\left[\mathrm{P}(\mathrm{e}) \wedge \tau(\mathrm{e}) \underline{\complement}_{\mathrm{T}} \mathrm{t}_{\mathrm{r}}\right]
$$

$$
\lambda \mathrm{P} \lambda \mathrm{e}\left[\mathrm{MXT}\left(\mathrm{e}, \mathrm{t}_{\mathrm{r}}\right) \wedge \neg \exists \mathrm{e}^{\prime}\left[\mathrm{P}\left(\mathrm{e}^{\prime}\right) \wedge \mathrm{e}^{\prime} \complement_{\mathrm{E}} \mathrm{e}\right]\right]
$$


The negation differs from the representation of does not in (22) insofar as it takes into account the reference time of the whole sentece. This works out properly for un-negated sentences and sentences with a negation dependent on the reference time, as the following examples show:

(29)

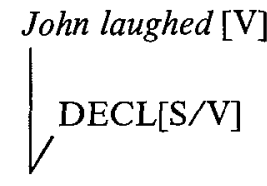

John laughed $[\mathrm{S}]$

(30)

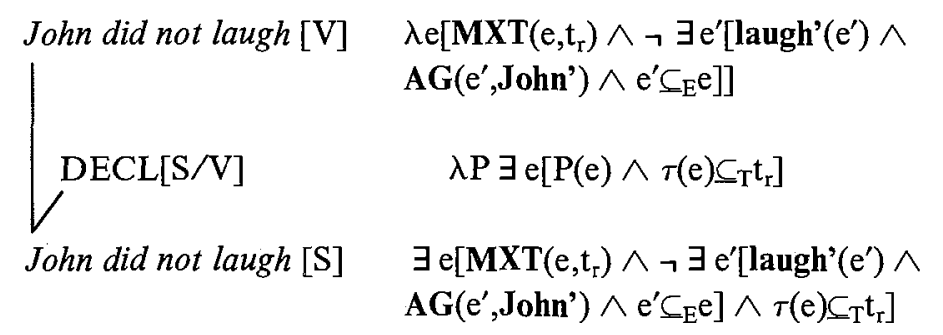

The first representation says that an event of John's laughing occurred during the reference time. The second one says that the maximal event of the reference time does not contain an event of John's laughing, that is, that John didn't laugh at any part of the reference time.

The price we have to pay for this analysis is to get along with two types of negations, one which does make reference to the reference time and one which doesn't. A possible reason why we do not get real ambiguities with sentences like John didn't laugh (yesterday) is that the negation which doesn't takes into account the reference time would produce a very weak reading: namely that at some time yesterday, there was no laughing by John. ${ }^{18}$

\section{QUANTIFICATION}

Another problem in event semantics is the treatment of quantifiers, which is most elegantly solved in the standard semantic theory of generalized quantifiers (GQ) (cf. Barwise \& Cooper 1981).

Several treatments of quantifiers have been proposed in event semantics (Parsons 1980, Schein 1986, Link 1987; the treatment of quantifiers in interval semantics by Cresswell 1977 could be easily carried over to event semantics). However, these analyses have various shortcomings; for example, it remains unclear how they can be extended to the full range of quantifiers treated by GQ Theory. Here, I will show that it is possible to incorporate the power of GQ theory once we have lattice event structures and the notion of maximal events at our disposal.

Consider the following examples:

\section{(31) Most girls sang.}

(32) Less than three girls sang.

(31) is a sentence with an increasing quantifier. It should be true if there was an event which contains a singing of most (that is, more than half of the) girls. (32), on the other hand, is a sentence with a decreasing quantifier. It cannot be paraphrased by 'there was an event which contained singing events of less than three girls', because this paraphrase allows for more girls to have sung as well. That is, the truth of (32) cannot be checked locally, but we must take into account maximal events, as with negation. To handle quantifiers uniformally, we can make reference to maximal events with increasing quantifiers as well.

Let us first define a function max which maps a relation between numbers and entities to a number, the highest number for which the relation holds:

(D 46) $\forall \mathrm{n} \forall \mathrm{R}\left[\max (\mathrm{R})=\mathrm{n} \leftrightarrow \exists \mathrm{x}\left[\mathrm{R}(\mathrm{x}, \mathrm{n}) \wedge \forall \mathrm{n}^{\prime}\left[\exists \mathrm{x}\left[\mathrm{R}\left(\mathrm{x}, \mathrm{n}^{\prime}\right)\right] \rightarrow \mathrm{n}^{\prime} \leq \mathrm{n}\right]\right]\right]$

Consider the event predicate less than three girls sing. It should hold of maximal events which contain the singing of one or two girls at most (or contain no singing of girls at all, a limiting case which should be filtered out by a pragmatic rule). To handle maximal events, we can either choose maximal events at the reference time (with MXT) or simple maximal events (with MXE); in the latter case, we get the following interpretation: 


$$
\begin{aligned}
& \text { sing }\left[\mathrm{V} / \mathrm{NP}_{\mathrm{s}}\right] \\
& \text { girl }[\mathrm{N} / \mathrm{NM}] \\
& \text { less than three } \\
& \text { girls }\left[\mathrm{NP}_{\mathrm{s}}\right] \\
& \text { less than three girls } \\
& \text { sing }[\mathrm{V}]
\end{aligned}
$$

for the classic analysis of the definite article because the condition of uniqueness is not met with expressions like the gold. The empirical generalization is that the definite article can be used with cumulative nominal predicates if they have a non-empty extension, and it can be used with quantized nominal predicates if they have a non-empty singular extension. This can be captured by the following analysis:

(35) a. the $\left[\mathrm{NP}_{s} / \mathrm{N}\right]$

$$
\begin{aligned}
& \lambda \mathrm{Q} \lambda \mathrm{P} \lambda \mathrm{e} \exists \mathrm{x}_{\mathrm{s}}\left[\mathrm{P}(\mathrm{e}) \wedge \mathrm{x}_{\mathrm{s}}=\iota \mathrm{x}[\mathrm{x}=\mathrm{FU} \mathrm{O}(\mathrm{Q}) \wedge \mathrm{Q}(\mathrm{x})]\right] \\
& \text { b. } \text { the three girls }\left[\mathrm{NP}_{\mathrm{s}}\right] \\
& \lambda \mathrm{P} \lambda \mathrm{e} \exists \mathrm{x}_{\mathrm{s}}\left[\mathrm{P}(\mathrm{e}) \wedge \mathrm{x}_{\mathrm{s}}=\iota \mathrm{x}\left[\mathrm{x}=\mathrm{FU} \mathrm{O}(\lambda \mathrm{x}[\operatorname{girl}(\mathrm{x} ; 3)]) \wedge \operatorname{girl}^{\prime}(\mathrm{x}, 3)\right]\right] \\
& \text { c. } \text { the girls }\left[\mathrm{NP}_{\mathrm{s}}\right] \\
& \lambda \mathrm{P} \lambda \mathrm{e} \exists \mathrm{x}_{\mathrm{s}}\left[\mathrm{P}(\mathrm{e}) \wedge \mathrm{x}_{\mathrm{s}}=\iota \mathrm{x}\left[\mathrm{x}=\mathrm{FU}_{\mathrm{O}}\left(\operatorname{girls}^{\prime}(\mathrm{x})\right) \wedge \operatorname{girls}(\mathrm{x})\right]\right]
\end{aligned}
$$

This is true if the total number of girls singing in the maximal event $\mathrm{e}$ is less than three. ${ }^{19}$

Consider as a second example the treatment of an increasing quantifier, most girls. This is at the same time a proportional quantifier, which means that we cannot specify an absolute number, but have to determine a proportion. In order to treat $\mathrm{i}$ ing and decreasing quantifiers alike, I assume that increasing quantifiers refer to maximal events as well.

\section{(34) most girls $\left[\mathrm{NP}_{\mathrm{s}}\right]$}

$$
\lambda \mathrm{P} \lambda \mathrm{e}\left[\operatorname{MXE}(\mathrm{e}) \frac{\max \left(\lambda \mathrm{n} \lambda \mathrm{x}_{s} \exists \mathrm{e}^{\prime}\left[\mathrm{P}\left(\mathrm{e}^{\prime}\right) \wedge \operatorname{girl}^{\prime}\left(\mathrm{x}_{s}, \mathrm{n}\right) \wedge \mathrm{e}^{\prime} \subseteq_{\mathrm{E}} \mathrm{e}\right]\right)}{\max \left(\lambda \mathrm{n} \lambda \mathrm{x}_{\mathrm{s}}\left[\operatorname{girl}^{\prime}\left(\mathrm{x}_{s}, \mathrm{n}\right)\right]\right)}>1 / 2\right]
$$

An event predicate like most girls sing, then, holds of maximal events which do contain singing events of more than half of the girls. ${ }^{20}$

It is obvious how the treatment of quantifiers given above can be extended to cover other numerical quantifiers like (exactly) three girls, more than three girls, between three and seven girls, an odd number of girls, etc.

This treatment of quantification must be extended in various directions to cover the wealth of possible quantifiers in natural languages. For example, it should be extended to mass noun quantification, as e.g. most wine, where we cannot resort to a given measure function, but must employ some measure function which is extensive for the domain in question. Here, I will treat three problems, namely definite NPs, cumulative quantification and distributive quantification.

Definite NPs, like the gold, the girls or the three girls, pose a problem

In this analysis, definite NPs contain terms of the form $\iota x\left[x=F_{0}(\delta) \wedge\right.$ $\delta(\mathrm{x})$ ], where $\delta$ is the nominal predicate. This expression refers to the maximal individual, so to speak, to which $\delta$ can be applied. Now consider two cases:

(i) If $\delta$ is cumulative and has a non-empty extension, then this maximal individual necessarily exists. Proof: $\delta$ has a fusion (because $\mathbf{O}$ and $\cup_{\mathbf{O}}$ constitute a complete lattice), and this fusion is itself in the extension of $\delta$ (because $\delta$ is cumulative).

(ii) If $\delta$ is quantized, then $\iota x\left[\mathrm{x}=\mathrm{FU}_{\mathrm{O}}(\delta) \wedge \delta(\mathrm{x})\right]$ exists only if $\delta$ has singular reference. That is, the condition of uniqueness emerges as a special case which only holds for quantized predicates (cf. also Link 1983). Proof: If $\delta$ has singular reference, then the fusion is identical to the only object in the extension of $\delta$ (because $\cup_{\mathrm{O}}$ is idempotent); but if $\delta$ is quantized without having singular reference, then the join of two different objects in the extension of $\delta$ (and therefore, the fusion of $\delta$ ) cannot be in the extension of $\delta$.

For cases like the girl, we could assume that the determiner the fills the number argument of the count noun relation by 1 :

(36) the $\left[\mathrm{NP}_{\mathrm{s}} /(\mathrm{N} / \mathrm{NM})\right]$

$$
\lambda \operatorname{R} \lambda \mathrm{P} \lambda \mathrm{e} \exists \mathrm{x}_{\mathrm{s}}\left[\mathrm{P}(\mathrm{e}) \wedge \mathrm{x}_{\mathrm{s}}=\iota \mathrm{x}\left[\mathrm{x}=\mathrm{FU}_{\mathrm{O}}(\mathrm{R}(1)) \wedge \mathrm{R}(\mathrm{x}, 1)\right]\right]
$$

Next, consider cumulative readings, as in the following example.

(37) Two girls ate seven apples. 
The readings we are looking for are those in which no more than seven apples are eaten. I call this readings cumulative after Scha (1981), who identified it with the example 500 Dutch firms own 2000 American computers, and not 'collective', as this term should be saved for examples like John and Mary (jointly) wrote a book. In example (37), there is no implication that the girls have eaten the apples jointly; it just says that there are two girls and seven apples such that the girls ate the apples in a way that no girl and no apple is left, but not necessarily jointly.

If we claim summativity with any thematic role, we are in a position to handle cumulative readings in an elegant way. For example, if there are two events, one to be described by (38.a), the other by (38.b),

(38) a. Mary ate three apples.

b. Susan ate four apples.

and if the apples Mary and Susan ate do not overlap (which is most plausible for consumed patient relations), then the sentence Mary and Susan ate seven apples can be derived if one assumes that the thematic relations are summative, and that the count noun meaning is based on an extensive measure function compatible with the object lattice.

(39) eat' $\left(e_{1}\right) \wedge \mathbf{A G}\left(e_{1}, M_{1}\right.$ ary' $) \wedge \operatorname{PAT}\left(e_{1}, y_{1}\right) \wedge$ apple' $\left(y_{1}, 3\right)$

eat' $\left(e_{2}\right) \wedge \mathbf{A G}\left(e_{2}\right.$, Susan' $\left.^{\prime}\right) \wedge \mathbf{P A T}\left(\mathrm{e}_{2}, \mathrm{y}_{2}\right) \wedge$ apple' $\left(\mathrm{y}_{2}, 4\right)$

$\neg \mathrm{y}_{1}{ }^{\circ} \mathrm{O} \mathrm{y}_{2}$

eat' $\left(\mathrm{e}_{1} \cup_{\mathrm{E}} \mathrm{e}_{2}\right) \wedge \mathbf{A G}\left(\mathrm{e}_{1} \cup_{\mathrm{E}} \mathrm{e}_{2}\right.$, Mary' $\cup_{\mathrm{O}}$ Susan' $) \wedge \operatorname{PAT}\left(\mathrm{e}_{1} \cup_{\mathrm{E}} \mathrm{e}_{2}, \mathrm{y}_{1} \cup_{\mathrm{O}} \mathrm{y}_{2}\right) \wedge$ apple' $\left(\mathrm{y}_{1} \cup \mathrm{O}_{2}, 7\right)$

Note that the derived sentence has rather weak truth conditions, as the relating of the apples to Mary and Susan remains unspecified. This is as it should be, as the different ways of relating them are not 'readings' of the sentence. In contrast to other theories of cumulative predication, most recently Gillon (1987) and Verkuyl (1988), this is a natural outcome of a simple rule (summativity of thematic relations) and need not be stated by a complicated rule involving quantification over partitions of sets and the like.

With this analysis, the treatment of cumulative readings becomes possible, if we analyze indefinite NPs as above.

(40) a. two girls $\left[\mathrm{NP}_{\mathrm{s}}\right] \quad \lambda \mathrm{P} \lambda \mathrm{e} \exists \mathrm{x}_{\mathrm{s}}\left[\mathrm{P}(\mathrm{e}) \wedge \operatorname{girl}\left(\mathrm{x}_{\mathrm{s}}, 2\right)\right]$

b. two girls ate seven apples [V]

$\lambda$ e $\exists \mathrm{x}_{\mathrm{s}} \exists \mathrm{x}_{\mathrm{o}}\left[\right.$ eat' $^{\prime}(\mathrm{e}) \wedge \mathbf{A G}\left(\mathrm{e}, \mathrm{x}_{\mathrm{s}}\right) \wedge \operatorname{PAT}\left(\mathrm{e}, \mathrm{x}_{\mathrm{o}}\right) \wedge$ apple' $\left(\mathrm{x}_{\mathrm{o}}, 7\right) \wedge$ $\left.\operatorname{girl}\left(x_{s}, 2\right)\right]$

This representation does not exclude that two girls ate more apples, or that more than two girls ate apples. But we arrive at a 'maximal' interpretation if we take into account the pragmatic rule (I). The reason is that $n$ girls ate $m$ apples entails $n^{\prime}$ girls ate $m^{\prime}$ apples if $\mathrm{n}^{\prime} \leq \mathrm{n}$ or $\mathrm{m}^{\prime} \leq \mathrm{m}$, so that the hearer can assume that the speaker chooses the highest values for $n, m$ to be maximally informative.

Finally, I will analyze the distributive readings of the sentence two girls ate seven apples, and I will concentrate on the reading where two girls ate seven apples each. We can give an interpretation of it by use of the notion of an atomic part of objects, $\mathbf{A T P}_{\mathrm{O}}$, as defined in (D 19). The basic idea, which was put forward in Link (1983), is that this sentence is true in this reading if there is an object $\mathrm{x}$ which consists of two girls, and for every atomic part $\mathrm{x}^{\prime}$ of $\mathrm{x}$ (that is, for every individual girl in $\mathrm{x}$ ) it holds that $\mathrm{x}^{\prime}$ ate seven apples. There are two possibilities to get this interpretation: Either we put the representation of distributivity into the subject NP or into the verbal predicate. In the latter case, I assume a verbal operator which manifests itself optionally in the adverbial each, which is to be bound to a specific syntactic variable.

(41)

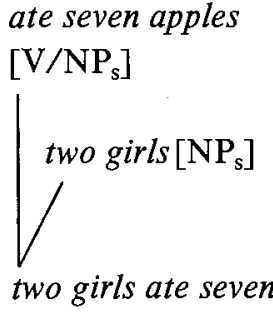

apples [V]

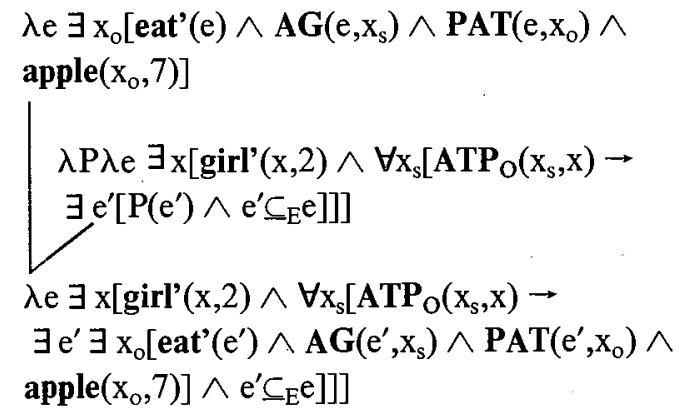


110 Manfred Krifka

(42)

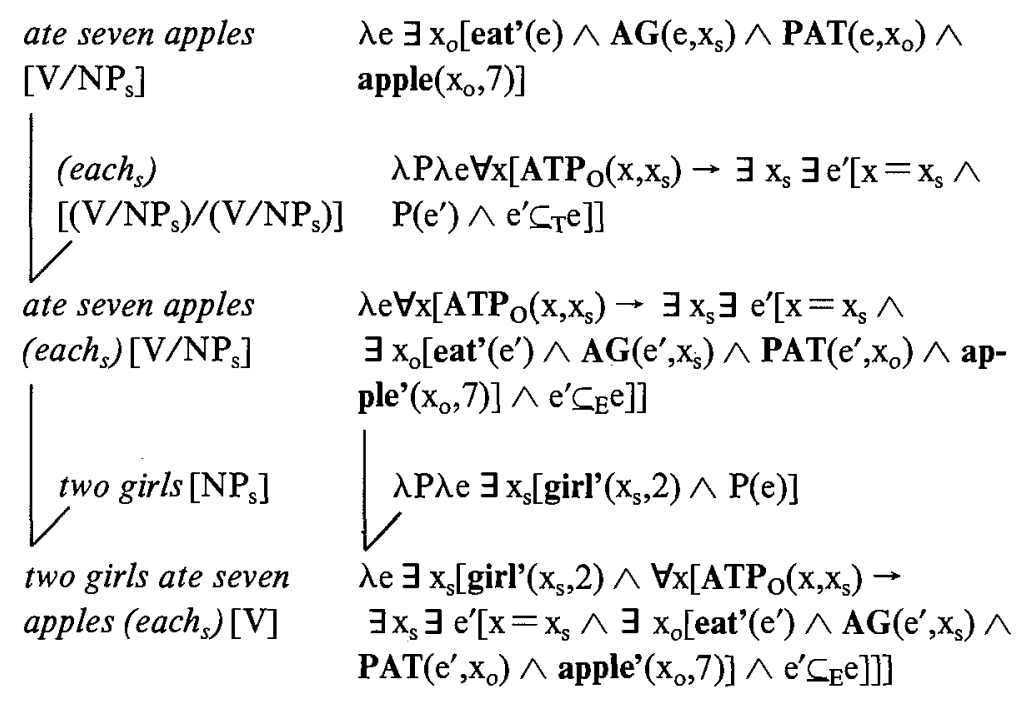

$\lambda \mathrm{e} \exists \mathrm{x}_{\mathrm{o}}\left[\right.$ eat' $(\mathrm{e}) \wedge \mathbf{A G}\left(\mathrm{e}, \mathrm{x}_{\mathrm{s}}\right) \wedge \boldsymbol{P A T}\left(\mathrm{e}, \mathrm{x}_{\mathrm{o}}\right) \wedge$ apple $\left.\left(x_{0}, 7\right)\right]$$$
\lambda P \lambda \operatorname{e} \forall x\left[\operatorname { A T P } _ { \mathrm { o } } ( \mathrm { x } , \mathrm { x } _ { \mathrm { s } } ) \rightarrow \exists \mathrm { x } _ { \mathrm { s } } \exists \mathrm { e } ^ { \prime } \left[\mathrm{x}=\mathrm{x}_{\mathrm{s}} \wedge\right.\right.
$$$$
\left.\left.\mathrm{P}\left(\mathrm{e}^{\prime}\right) \wedge \mathrm{e}^{\prime} \subseteq_{\mathrm{T}} \mathrm{e}\right]\right]
$$

Both representations describe the same type of events; moreover, the combination of the first representation of two girls with the verbal predicate of the second representation, ate seven apples (each), describes the same type of events.

\section{CONCLUSION}

To summarize, I hope to have made it clear that a semantic representation is feasible in which the intuitive similarities between the reference type of noun phrases and the temporal constitution of verbal expressions is captured in a simple and revealing way. I have shown how one can explain that the reference type of a noun phrase affects the temporal constitution of a verbal expression, and I have argued to employ measure functions to explain phenomena of quantization both in the nominal and in the verbal domain. Furthermore, I have shown that in assuming lattices as model structures, we gain an interesting treatment of negation and quantification in event semantics.

There are different directions in which the analysis developed above can be extended. One is the exploration of other verbal modifiers which bear on the temporal constitution of the complex verbal construction. Locative adverbials are an example. I have shown how measure functions on times can yield derived measure functions on events based on the temporal trace function, which can capture the semantics of durative adverbials like for two hours. In a similar manner, we can derive event measure functions from measure functions for distances based on a local trace function to describe locative measure adverbials like for two miles. Furthermore, the influence of locative and directional adverbials, as in/ to/towards the post office, on the temporal constitution of a complex verbal expression can be described easily.

Another direction is the explanation of seemingly strange markings of verbal and nominal categories. In Krifka (1986) I have shown how one can explain that the progressive aspect can be marked on the noun phrase (as with the Finnish partitive and the less common German prepositional object construction, e.g. an einem Apfel essen vs. einen Apfel essen). Similarly, I have explained how perfective aspect can have an effect on the interpretation of noun phrases in languages which lack definite articles, as e.g. Slavic languages and Chinese (in these languages, a perfective verbal expression with a nominal object enforces a definite interpretation of the object). Another case which can be explored in a rigid manner is the semantics of aktionsarten. For example, in many languages which have a frequentative verb form it remains unspecified whether the meaning of this aktionsart applies to verbs or to their arguments, that is, whether they express the existence of many events or the existence of many objects subjected to an event.

\section{NOTES}

* This article has developed from my doctoral thesis at the University of Munich, Krifka (1986). I learned a lot from my supervisors, Theo Vennemann and Godehard Link. And there are many more people who helped to clarify my ideas and their presentation: Rainer Bäuerle, Johan van Benthem, David Dowty, Hana Filip, Franz Guenthner, Sebastian Löbner, Jan Tore Lønning, Uwe Mönnich, Leonoor Oversteegen, Barbara Partee, Craige Roberts, Arnim von Stechow, Henk Zeevat, Barbara Zimmermann, Ede Zimmermann, and surely more. Thanks to them all.

1. I have given the preorder and concatenation of a measure function $\mu$ as $\leq_{\mu}$ and $+_{\mu}$, respectively. This is implausible in one respect, as measure functions of the same dimension, e.g. ounce and gram, should share their preorder and concatenation. There are ways to capture this fact (cf. e.g. Lønning 1987), but for reasons of simplicity I will keep to the notation introduced above.

2. One could argue that, e.g., a proper part of a glass of wine is still a glass of wine, because there are smaller glasses, or a glass which is not quite full of wine still must count as a glass of wine. I ignore these matters of vagueness here and assume a strict interpretation. Another possible reconstruction would be to represent the count noun cow by COW and to put the NU-Operator into the representation of the numeral, e.g. five as $\lambda \mathrm{P}, \mathrm{x}[\mathrm{P}(\mathrm{x}) \wedge$ $\mathrm{NU}(\mathrm{P})(\mathrm{x})=5$ ]. However, we would then need a different representation of numerals for measure constructions like five head of cattle. 
4. This means, contrary to common assumptions but compatible with observations in McCawley (1968), that the plural is not the semantically marked number.

5. This example is due to Barbara Partee.

6. Here, $\mathrm{PP}$, for 'prepositional phrase', is equivalent to $(\mathrm{V} / \mathrm{X}) /(\mathrm{V} / \mathrm{X})$, where $\mathrm{X}$ is a string of categories which is possibly empty, in which case $\mathrm{V} / \mathrm{X}=\mathrm{V}$.

7. I should make it clear that it is by no means necessary for me to assume thematic relations. For example, I could endorse a semantic representation of drink as $\lambda \mathrm{e}\left[\operatorname{drink}^{\prime}\left(\mathrm{e}, \mathrm{x}_{\mathrm{s}}, \mathrm{x}_{\mathrm{o}}\right)\right]$. The rules I give later in terms of thematic relations could then be given in terms of a specific argument of a specific class of verb, e.g. the object argument of verba efficiendi. However, the assumption of thematic relations allows a more perspicuous formulation of these rules. 8. The use of standard variables seems to violate the compositionality principle, as a complex semantic representation depends on the :dentity of some parts of their subrepresentation. However, note that this identity is encoded in the syntactic rules of category combination. The rules proposed here perhaps show a more intricate interaction between syntactic and semantic rules than usual. Furthermore, they require the syntactic arguments of a verb to be syntactically characterized in a unique way; otherwise we would end up with the same variable for different arguments. This is guaranteed by the so-called Stratal Uniqueness Law (cf. Perlmutter \& Postal 1977).

9. Note that the semantic type of NPs and PPs is the same in this treatment: both are verb modifiers, that is, event predicate modfiers. NPs differ from PPs only insofar as they contain a variable which is related to a free variable in the verb. One may ask how prepositions are treated in this framework. Semantically, they end up as noun phrase modifiers which provide a noun phrase with a semantic relation. Let $\mathrm{PP} / \mathrm{NP}_{\mathrm{c}}$ the category of prepositions governing noun phrases of category $\mathrm{NP}_{\mathrm{c}}$. To avoid variable conflicts, we have to assume special variables for prepositional cases, e.g. $x_{p}$ for objects governed by prepositions. We end up with analysis like the following one (here, $R$ is a variable of the type of NPrepresentations):

$$
\underbrace{\operatorname{in}\left[\mathrm{PP} / \mathrm{NP}_{\mathrm{p}}\right]}_{\text {in a kitchen }[\mathrm{PP}]} \underset{\lambda \mathrm{P} \lambda \lambda \mathrm{e} \exists \mathrm{x}_{\mathrm{p}}\left[\mathrm{P}(\mathrm{e}) \wedge \mathrm{IN}\left(\mathrm{e}, \mathrm{x}_{\mathrm{p}}\right) \wedge \text { kitchen' }^{\prime}\left(\mathrm{x}_{\mathrm{p}}, 1\right)\right]}{\lambda R \lambda \mathrm{P} \lambda \mathrm{e}\left[R\left(\lambda \mathrm{e}\left[\mathrm{P}(\mathrm{e}) \wedge \mathrm{IN}\left(\mathrm{e}, \mathrm{x}_{\mathrm{p}}\right)\right]\right)(\mathrm{e})\right]}
$$

10. One might ask whether there is a way to capture anaphoric relations in this approach as NPs always have narrow scope. But we could easily define NPs like $\lambda x[$ apple' $(x, 1) \wedge$ $\mathrm{x}=\mathrm{d}]$ for the specific reading of an apple and $\lambda \mathrm{x}[\mathrm{x}=\mathrm{d}]$ for a pronoun coreferring to the apple, with $d$ as a discourse referent in the style of Kamp (1981) and Heim (1982).

11. To distinguish between them on the event level seems to be the wrong way to characterize their difference. Cf. for these approaches Bennett (1977), who distinguished them by open and closed intervals, and Galton (1984), Bach (1986), Verkuyl (1988), who assumed different sorts of entities.

12. With the definitions of section (5), we can make this function more precise. First, we define the final temporal point (FTP) of an event as

$$
\forall \mathrm{e} \forall t\left[F T P(e)=t \rightarrow T_{a}(t) \wedge t \varsigma_{T} \tau(e) \wedge \forall t^{\prime}\left[t^{\prime} \varsigma_{T} \tau(e) \rightarrow{ }^{t}<<_{T} t^{\prime}\right]\right]
$$

Then we can define the terminal point (TP) of an event e under a description $\mathbf{P}$ as follows:

$\forall \mathrm{VPP} \forall t\left[\mathbf{T P}(\mathrm{e}, \mathrm{P})=\mathrm{t} \rightarrow \mathbf{P}(\mathrm{e}) \wedge \mathbf{F T P}(\mathrm{e})=\mathrm{t} \wedge \neg \exists \mathrm{e}^{\prime}\left[\mathbf{P}\left(\mathrm{e}^{\prime}\right) \wedge\left[\mathrm{e}^{\prime} \subseteq_{\mathrm{E}} \mathrm{e} \vee \mathrm{e} \complement_{\mathrm{E}} \mathrm{e}\right] \wedge \mathbf{F T P}(\mathrm{e})\right.\right.$ $<_{\mathrm{T}}$ FTP $\left.\left.\left(\mathrm{e}^{\mathrm{e}}\right)\right]\right]$
13. Note that there is another interpretation of write, as in the secretary wrote this letter ten times. In this reading, write denotes the realization of a type. As a type can be realized more than once, this reading fails to be unique for events and consequently allows for durative adverbials, as in the secretary wrote this letter for three years.

14. However, other interpretations are possible, a point which was made clear to me by Sebastian Löbner. For example, if John and Mary are paid for their singing, then they could argue to have sung for 4 hours. Consequently, we must assume different standardizations and concatenations for this interpretation of the measure function.

15. Note that there are scope restrictions for time adverbials in other cases. For example, they cannot have scope over sentence adverbs like fortunately (cf. * For two hours, John fortunately ate). This can be explained if we assume that sentence adverbs apply to propositions, yielding propositions again, whereas durative adverbials cannot apply to propositions.

16. Here, AUX is short for $\left(\mathrm{V} / \mathrm{NP}_{\mathrm{s}}\right) /\left(\mathrm{V} / \mathrm{NP}_{\mathrm{s}}\right)$.

17. Note, however, that negated event predicates are not cumulative either. For example, the event predicate John did not eat five apples may apply to two maximal events which contain the eating of two and three apples by John, respectively, but not to the sum of these maximal events.

18. Another possibility to handle negation would be to assume just the negation dependent on reference time, and furthermore that time adverbials like for two hours existentially bind the open reference time variable.

19. Note that $\mathrm{n}$ does not count just the maximal group present in any subevent of $\mathrm{e}^{\prime}$ and allow for more girls to have sung in $\mathrm{e}^{\prime}$ as a whole. For if we have two parts of $e^{\prime}, e_{1}$ and $e_{2}$, and both consist of singings of different groups of two girls, then their sum $e_{1} \cup_{E} e_{2}$ is a part of $e^{\prime}$ as well, this sum would be the singing of four girls, and hence would be excluded by the max-subformula which requires that the maximal number of girls singing is less than three.

20. In these examples, I have assumed that the 'resource situation' (cf. Barwise \& Perry 1983) which determines the quantifiers is the whole universe. But it is easy to have an explicit parameter which restricts the extension of the noun to those entities belonging to the resource situation.

\section{REFERENCES}

Allan, Keith: 1977, 'Classifiers', Language 53, 285-311.

Atlas, David \& Stephen Levinson: 1981, 'H-clefts, informativeness, and logical form: radical pragmatics (revised standard version)', in P. Cole (ed.), Radical Pragmatics, Academic Press, New York, 1-61.

Austin, John: 1950, 'Truth', in Proceedings of the Aristotelian Society, Supp. vol. XXIV. Reprinted in Philosophical Papers, Oxford University Press, Oxford, 117-133.

Bach, Emmon: 1986, 'The Algebra of Events', Linguistics and Philosophy 9, 5-16.

Barwise, Jon \& Robin Cooper: 1981, 'Generalized Quantifiers and Natural Language' Linguistics and Philosophy 4, 159-219.

Barwise, Jon \& John Perry: 1983, Situations and Attitudes. Cambridge, Mass: MIT Press. Barwise, Jon \& John Etchemendy: 1987, The Liar. An Essay on Truth and Circularity. Oxford University Press, Oxford.

Bäuerle, Rainer: 1979, Temporale Deixis, temporale Frage. Gunter Narr, Tübingen.

Bäuerle, Rainer: 1987, Ereignisse und Repräsentationen. Habilitationsschrift, Universität Konstanz.

Bennett, Michael: 1977, 'A Guide to the Logic of Tense and Aspect in English'. Logique et Analyse 20, 491-517. 
van Benthem, Johan: 1983, The Logic of Time. A Model-Theoretic Investigation into the Varieties of Temporal Ontology and Temporal Discourse. D. Reidel, Dordrecht.

Carlson, Greg N.: 1984, 'Thematic Roles and their Role in Semantic Interpretation'. Linguistics $22,259-279$.

Cartwright, Helen: 1975, 'Amounts and Measures of Amount'. Noûs 9, 143-164.

Castañeda, Hector-Neri: 1967. 'Comments on D. Davidson's "The Logical Form of Action Sentences "', in N. Rescher (ed.), The Logic of Decision and Action, Pittsburgh University Press, Pittsburgh, 104-112.

Cresswell, Max: 1977, 'Interval Semantics and Logical Words', in Chr. Rohrer (ed.), On the Logical Analysis of Tense and Aspect, Tübingen: Narr.

Davidson, David: 1967, 'The Logical Form of Action Sentences', in N. Rescher (ed.), The Logic of Decision and Action, Pittsburgh University Press, Pittsburgh, 81-95.

Dowty, David: 1979, Word Meaning and Montague Grammar. The Semantics of Verbs and Times in Generative Semantics and Montague's PTQ, Reidel, Dordrecht.

Dowty, David: 1987a, 'On the Semantic Content of the Notion "Thematic Role"', to appear in G. Chierchia, B. Partee \& R. Turner (eds.), Property Theory, Type Theory and Natural Language Semantics, Reidel, Dordrecht.

Dowty, David: 1987b, 'Events, Aspects, and NP Semantics', talk presented at the Conference on Logic and Linguistics, Stanford, July 10-11, 1987.

Fauconnier, Gilles: 1978, 'Implication Reversal in a Natural Language', in F. Guenthner \& S. Schmidt (eds.), Formal Semantics and Pragmatics for Natural Language, Reidel, Dordrecht, 289-301.

François, Jean: 1985, 'Aktionsart, Aspekt und Zeitkonstitution', in Chr. Schwarze \& D. Wunderlich (eds.), Handbuch der Lexikologie, Athenaeum, Kronberg, 229-249.

Galton, Anthony: 1984, The Logic of Aspect. An Axiomatic Approach. Oxford: Clarendon Press.

Garey, Howard B.: 1957, 'Verbal Aspects in French', Language 33, 91-110.

Gillon, Brendan S.: 1987, 'The Readings of Plural Noun Phrases in English', Linguistics and Philosophy 10, 199-220.

Grice, Paul: 1967, 'Logic and Conversation'. William James Lectures, Harvard University, Partly published as 'Logic and Conversation', in P. Cole \& J.L. Morgan (eds.) 1975, Syntax and Semantics 3: Speech Acts, Academic Press, New York, 41-58.

Heim, Irene: 1982, The Semantics of Definite and Indefinite Noun Phrases, Ph.D. dissertation, University of Massachusetts at Amherst.

Hinrichs, Erhard: 1985, A Compositional Semantics for Aktionsarten and NP Reference in English. Ph.D. Dissertation, Ohio State University.

Hoepelman, Jakob: 1976, 'Mass. Nouns and Aspects, or: Why We Can't Eat Gingercake in an Hour', Amsterdam Papers in Formal Grammar 1.

Hoepelman, Jakob, \& Christian Rohrer: 1980, 'On the Mass-Count Distinction and the French Imparfait and Passé Simple', In Chr. Rohrer (ed.), Time, Tense, and Quantifiers, Niemeyer, Tübingen.

Horn, Larry: 1972, On the Semantic Properties of the Logical Operators in English. Indiana University Linguistics Club, Bloomington.

Humberstone, I. L.: 1979, 'Interval Semantics for Tense Logics'. Journal of Philosophical Logic 8, 171-196.

Jackendoff, Ray: 1972, Semantic Interpretation in Generative Grammar, MIT Press, Cambridge.

Kamp, Hans: 1981, 'A Theory of Truth and Semantic Representation', in J. Groenendijk,

T.M. Jansen, M. Stokhof (eds.), Formal Methods in the Study of Language, Mathematisch Centrum, Amsterdam, Vol. 1, 277-322.

Krifka, Manfred: 1986, Nominalreferenz und Zeitkonstitution. Zur Semantik von Massentermen, Pluraltermen und Aspektklassen. Doctoral Dissertation, Universität München. To appear 1989, Fink Verlag, Munich.
Leisi, Ernst: 1953, Der Wortinhalt. Seine Struktur im Deutschen und Englischen. Heidelberg: Quelle und Meyer.

Link, Godehard: 1983, 'The Logical Analysis of Plurals and Mass Terms: A Lattice-Theoretical Approach', in R. Bäuerle, Chr. Schwarze \& A.v. Stechow (eds.), Meaning, Use, and Interpretation of Language, de Gruyter, Berlin, 302-323.

Link, Godehard: 1987, 'Algebraic Semantics for Event Structures', In J. Groenendijk, M. Stokhof \& F. Veltman (eds.), Proceedings of the Sixth Amsterdam Colloquium, University of Amsterdam, Institute for Language, Logic and Information, 243-262.

Lønning, Jan Tore: 1987, 'Mass Terms and Quantification', Linguistics and Philosophy 10, $1-52$.

McCawley, James D.: 1968, Review of 'Current Trends in Linguistics 3: Theoretical Foundations', Language 44, 556-593.

Parons, Terence: 1980 'Modifiers and Quantifiers in Natural Language', Canadian Journal of Philosophy Suppl. Vol. IV, 29-60.

Partee, Barbara: 1973, 'Opacity, Coreference, and Pronouns', in D. Davidson \& G. Harman (eds.), Semantics of Natural Language, Reidel, Dordrecht.

Perlmutter, David M. \& Paul Postal: 1977. 'Some Proposed Laws of Basic Clause Structure', in D.M. Perlmutter (ed.), Studies in Relational Grammar, Vol. 1, Chicago University Press, Chicago. 81-128.

Platzack, Christer: 1979, The Semantic Interpretation of Aspect and Aktionsarten. A Study of Internal Time Reference in Swedish, Foris, Dordrecht.

Quine, Williard v.O.: 1960, Word and Object, MIT Press, Cambridge, Mass.

Scha, Remko: 1981, 'Distributive, Collective, and Cumulative Quantification', in J. Groenendijk, T. Janssen \& M. Stokhof (eds.), Formal Methods in the Study of Language, Mathematisch Centrum, Amsterdam, Vol. 2, 483-512.

Schein, Barry: 1986, Event Logic and the Interpretation of Plurals. Ph.D.-Dissertation, MIT. Suppes, Patrick, \& Joseph L. Zinnes: 1963, 'Basic Measurement Theory', in R.D. Luce e.a. (eds.), Handbook of Mathematical Psychology, Vol. 1, Wiley, New York, 2-76.

Taylor, Barry.: 1977, 'Tense and Continuity'. Linguistics and Philosophy 1, 199-220.

ter Meulen, Alice: 1984, 'Events, Quantities, and Individuals', In F. Landman \& F. Veltman (eds.), Varieties of Formal Semantics, Foris, Dordrecht, 259-280.

Vendler, Zeno: 1957, 'Verbs and Times', Philosophical Review 66, 143-160. Also in Z. Vendler, 1967, Linguistics and Philosophy, Cornell University Press, Ithaca, 97-121.

Verkuyl, Henk J.: 1972, On the Compositional Nature of the Aspects, Reidel, Dordrecht.

Verkuyl, Henk J.: 1988, 'Aspectual Asymmetry and Quantification', in V. Ehrich \& H. Vater (eds.), Temporalität. (Proceedings of the Heidelberg workshop on Tense and Aspect, February 1986). Tübingen: Niemeyer. 